\title{
MIXING EFFECTS AND HYDRODYNAMICS OF VORTEX RINGS
}

\section{by}

Anil Rohatgi, Dipl.-Ing., P.Eng"•

\begin{abstract}
A project report
submitted to the Faculty of Graduate

studies in partial fulfillment of

the requirements for the degree of

Master of Engineering
\end{abstract}

McMaster University

Hamilton, Ontario, Canada

June, 1978

$-i-$ 
TITLE: Mixing effects and hydrodynamics of vortex rings. AUTHOR: Anil Rohatgi, Diplom-Ing (Technical University of Braunschweig, W. Germany)

SUPERVISOR : Dr. M.H.I. Baird

NO. OF PAGES $i-x, \quad 1-90$

SCOPE AND CONTENT:

Vortex rings are considered a promising means of mixing stratified fluids, e.g. in the blending of oils and the destabilisation of thermocline in harbours and lakes. In the presence of pollutants, a thermocline causes a deterioration in water quality and produces environmental problems.

The first two chapters discuss the history of vortex rings and the experimental procedures used to obtain stratification of fluids in a laboratory tank. Chapter 3 describes the energy relationships of vortex rings and provides an expression for the minimum potential energy required to mix a given stratified fluid. The results are given in Chapter 4 and the energy and volumetric efficiencies are discussed in Chapter 5.

Generation of large and powerful rings for industrial mixing purposes is discussed in Chapter 6, the hydrodynamic testing of these rings produced at a $25.4 \mathrm{~cm}$ orifice is discussed in Chapter 8. The conclusions from both the laboratory mixing tests and the hydrodynamic testing of large rings are given in Chapter 9. 


\section{ABSTRACT}

Ring vortices, produced at a $6.35 \mathrm{~cm}$ orifice, have been used to mix stratified fluids in a laboratory tank. The lighter fluid was ordinary tap water and the denser fluid consisted of sodium chloride solutions. A visual technique based on acid/base titration was used to specify both the degree of mixing and the completion of mixing. Four different independent variables were considered; density difference of the unmixed fluids, volume fraction occupied by the denser fluid, air injection time and air pressure. The energy efficiencies, based on the energy of the rings and theoretical potential energy needed to mix a stratified fluid, were 9 to 30\%, which were considerably higher than values obtained from the literature on impeller mixing. The volumetric efficiencies were generally greater than unity, i.e. the amount of lighter liquid contained in the number of ring vortices required for adequate mixing was less than the original volume of lighter liquid.

For testing possible future applications of ring vortices in oil-blending operations, destratification of lakes, harbours, and man-made dams, a large vortex generator with a $25.4 \mathrm{~cm}$ orifice was designed and built. The hydrodynamic testing of these stable and powerful rings under water indicated their range to be a maximum of $55.4 \mathrm{~m}$ and commonly $20-30 \mathrm{~m}$. The distance versus time data were consistent with a square-law (i.e. turbulent) drag mechanism. The early suggestion by Reynolds that vortex rings conserve their linear momentum was not confirmed. 


\section{ACKNOWLEDGEMENTS}

The work described in this project report was supervised by Dr. M.H.I. Baird of the Department of Chemical Engineering. The author is extremely grateful to his supervisor for his guidance, interest and constructive encouragement throughout this work.

The author is also grateful to the management of the Canada Centre of Inland Waters for providing their facilities and personnel for the hydrodynamic testing of large vortex rings.

Financial assistance from McMaster University and from the National Research Council of Canada is gratefully acknowledged。 


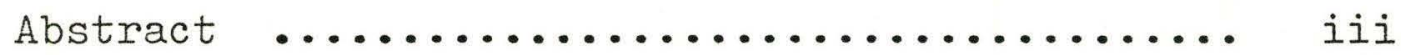

Acknowledgements $\quad \ldots \ldots \ldots \ldots \ldots \ldots \ldots \ldots$ iv

Contents $\quad \ldots \ldots \ldots \ldots \ldots \ldots \ldots \ldots \ldots \ldots \ldots$ v

Figures $\quad$....................... viii

Tables $\quad \ldots \ldots \ldots \ldots \ldots \ldots \ldots \ldots \ldots \ldots \ldots \ldots \ldots \ldots \ldots \ldots$

Mixing of Stratified Fluids with Ring Vortices

Chapter 1 Introduction

1.1 Mixing of Stratified Fluid $\quad \ldots \ldots \ldots \ldots \ldots \ldots \ldots . . \ldots$

1.2 Conventional Approaches to the Problem ......... 3

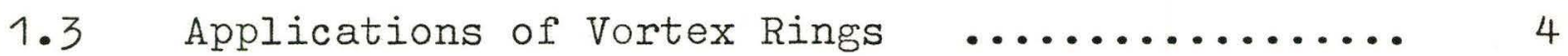

1.4 History of Vortex Rings $\quad \ldots \ldots \ldots \ldots \ldots \ldots$

1.5 Objective $\ldots \ldots \ldots \ldots \ldots \ldots \ldots \ldots \ldots \ldots \ldots \ldots \ldots$

Chapter 2 Experimental Apparatus and Procedure

2.1 Vortex Generator and Test Tank ............ 10

2.2 Stratification Procedure $\quad \ldots \ldots \ldots \ldots \ldots \ldots \ldots \ldots$

2.3 Degree of Mixing $\quad \ldots \ldots \ldots \ldots \ldots \ldots \ldots \ldots \ldots \ldots \ldots$

$2.4 \mathrm{Acid} /$ Base/Indicator $\ldots \ldots \ldots \ldots \ldots \ldots \ldots \ldots \ldots \ldots$

2.5 Experimental Procedure $\ldots \ldots \ldots \ldots \ldots \ldots \ldots \ldots \ldots$

2.6 Ranges of Variables Studied $\quad \ldots \ldots \ldots \ldots \ldots \ldots \ldots$

Chapter 3 Energy Relationships

3.1 Theoretical Mixing Energy Required for a Stratified

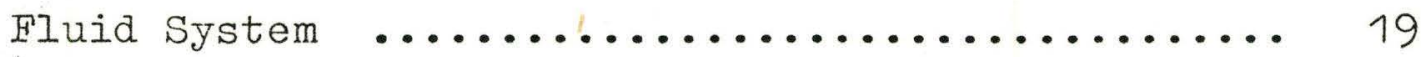

3.2 Efficiency of Mixing $\quad \ldots \ldots \ldots \ldots \ldots \ldots \ldots \ldots \ldots . . \ldots 2$

3.2.2 Volumetric Mixing Efficiency .............. 25 
3.3 Energy Available in a Vortex Ring ........... 26

Chapter 4 Results $\ldots \ldots \ldots \ldots \ldots \ldots \ldots \ldots \ldots \ldots \ldots \ldots \ldots . \ldots \ldots$

4.1 Unmixed Liquid $\quad \ldots \ldots \ldots \ldots \ldots \ldots \ldots \ldots \ldots \ldots \ldots \ldots$

Chapter 5 Discussion

5.1 Design of Vortex Generator ................ 29

5.2 Reproducibility of Experimental Results ........ 31

5.3 Comparison of Energy Efficiency in an Impeller

Mixer in a Vortex Mixer ..................... 31

5.4 Effect of Air Pressure $\quad \ldots \ldots \ldots \ldots \ldots \ldots \ldots . \ldots 32$

5.5 Effect of Liquid Density $\quad \ldots \ldots \ldots \ldots \ldots \ldots \ldots \ldots$

5.6 Effect of Vortex Formation Time ............. 40

5.7 Effect of Relative Proportions of Light and

Dense Iiquid $\quad \ldots \ldots \ldots \ldots \ldots \ldots \ldots \ldots \ldots \ldots \ldots \ldots \ldots \ldots \ldots \ldots \ldots$

Large Vortex Rings : Generation and Hydrodynamic Testing Chapter 6

6.1 Introduction $\quad \ldots \ldots \ldots \ldots \ldots \ldots \ldots \ldots \ldots \ldots \ldots \ldots$

6.2 Experimental Apparatus $\quad \ldots \ldots \ldots \ldots \ldots \ldots \ldots \ldots \ldots . . \ldots 7$

6.2.1 Test Tank $\quad$................. 47

6.2.2 Generation of Large Vortex Rings ........... 49

6.2.3 Float Tank and Rider For Momentum Measurements .... 51

6.3 Procedures

6.3 .1 Range and Velocity ..................... 52

6.3.2 Nature of Drag Forces Acting on a Large Vortex Ring ..53

6.3.3 Momentum of a Large Vortex Ring ................ 54

6.3.4 Experimental Determination of Momentum of a

Large Vortex Ring ........................ 55 
7.1 Velocity Determination of a Vortex Ring at

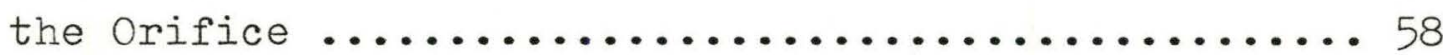

7.2 Vortex Ring Momentum Estimation ....................... 7.2.1 Float Tank's Velocity Estimation ............ 58 7.2.2 Momentum Measurement of the Vortex Ring at Orifice

Chapter 8 Discussion of Results .................. 80 8.1 Range and Velocity $\quad \ldots \ldots \ldots \ldots \ldots \ldots \ldots . \ldots . \ldots$ 8.2 Laminar Versus Turbulent Model for the Estimation

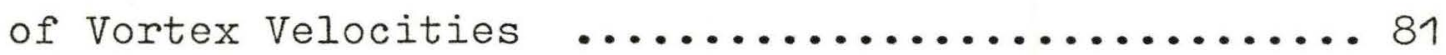
8.3 Vortex Ring Momentum Estimation .............. 82 Chapter 9 Conclusions $\quad \ldots \ldots \ldots \ldots \ldots \ldots \ldots \ldots \ldots \ldots$ 9.1 Conclusions Based on Mixing Tests .............. 85 9.2 Conclusions Based on Large Scale Hydrodynamic

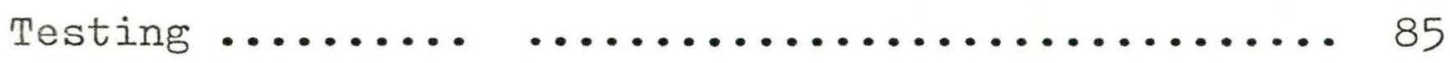

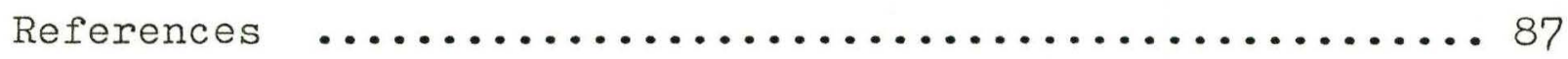
Nomenclature $\quad \ldots \ldots \ldots \ldots \ldots \ldots \ldots \ldots \ldots \ldots \ldots \ldots . \ldots . \ldots . \ldots . \ldots$ 


\section{FIGURES}

1 Schematic experimental arrangement for stratified fluids mixing with ring vortices $\ldots \ldots \ldots \ldots . \ldots . . . .9$

2 Change in the potential energy of a stratified fluid after it has been completely mixed ............ 19

3 Effect of pressure on performance $\ldots \ldots \ldots \ldots \ldots \ldots 33$

4 Effect of denser fluid density on performance ..... 37

4a Effect of denser fluid density on performance ...... 38

5 Effect of air injection time on performance ..... 41

6 Effect of volume fraction occupied by denser fluid on performance $\quad \ldots \ldots \ldots \ldots \ldots \ldots \ldots \ldots \ldots .44$

7 Schematic experimental arrangement for generation of large ring vortices, and measurement of ring velocity and momentum $\ldots \ldots \ldots \ldots \ldots \ldots \ldots \ldots \ldots .48$

8 Inner working of "Air Cannon" $\ldots \ldots \ldots \ldots \ldots \ldots \ldots$

Comparison of measured values of distance vs time of large vortex rings with fitted values from laminar and turbulent drag models, the parameter being the operating pressure.

$9 \quad$ Laminar drag model, pressure $275.8 \mathrm{kPa} \quad \ldots \ldots \ldots \ldots \ldots 63$

10 Turbulent drag model, pressure $275.8 \mathrm{kPa} \ldots \ldots \ldots \ldots .64$

11 Laminar drag model, pressure $344.7 \mathrm{kPa} \ldots \ldots \ldots \ldots .65$

12 Turbulent drag model, pressure $344.7 \mathrm{kPa} \ldots \ldots \ldots \ldots 6$

13 Iaminar drag model, pressure $413.7 \mathrm{kPa} \quad \ldots . .67$

14 Turbulent drag model, pressure $413.7 \mathrm{kPa} \ldots \ldots . . .68$

15 Laminar drag model, pressure $482.6 \mathrm{kPa}$........ 69

16 Turbulent drag model, pressure $482.6 \mathrm{kPa}$......... 70 
17 Float tank's displacement vs time, $p=275.8 \mathrm{kPa}$, Float tank@5,10,15 m

18 Float tank's displacement vs time, $\mathrm{p}=344.7 \mathrm{kPa}$, Float tank $5,10 \mathrm{~m} \ldots \ldots \ldots \ldots \ldots \ldots \ldots \ldots \ldots \ldots$

18a Float tank's displacement vs time, $p=344.7 \mathrm{kPa}$, Float tank $15 \mathrm{~m}$............................

19 Float tank's displacement vs time, $p=413.7 \mathrm{kPa}$

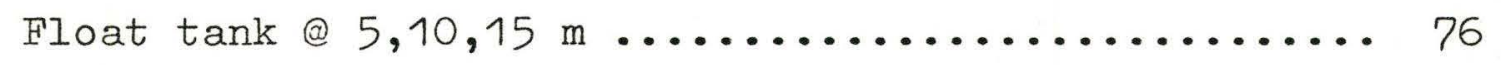


1 Range of variables studied ..................... 17

2 Scheme of experiments on stratified liquid mixing .... 28

3 Effect of air pressure on performance ............. 34

4 Effect of denser fluid density on performance ...... 39

5 Effect of injection time $t_{i}$ on performance $\ldots . . .442$

6 Effect of dense liquid fraction on performance ...... 45

7 Distance vs time measurements for large vortex ring velocity determination; $p=275.8,344.7 \ldots \ldots 59$

7a Distance vs time measurements for large vortex velocity determination; $p=413.7,482.7 \quad \ldots \ldots \ldots \ldots 60$

8 Determination of large vortex ring velocity at $\mathrm{X}=0$, by non-linear regression of measured data.

9 Variance analysis of laminar and turbulent drag

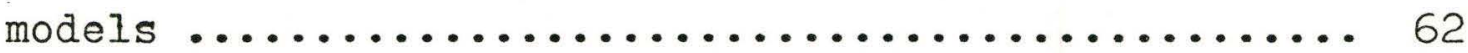

10 Momentum measurements at CCIW with float tank (eff. mass $1514 \mathrm{~kg}$ ) Displacements of float tank given in $\mathrm{cm} . \quad \ldots \ldots \ldots \ldots \ldots \ldots \ldots \ldots \ldots \ldots \ldots \ldots \ldots$

10a Summary of averaged displacements of float tank, vs. time 72

11 Determination of momentum of large vortex rings and comparison with Baird's method ............. 77 
Laboratory testing of ring vortices for mixing stratified fluids.

Generation and hydrodynamic testing of large vortex rings for possible future applications in industrial mixing. 
CHAPTER 1

INTRODUCTION

1.1 MIXING OF STRATIEIED FLUIDS: It has undoubtedly been known from prehistoric times that small shallow lakes tend to feel warmer to a swimmer than do large lakes, and in some cases the phenomenon of strong surface heating must have been similarly experienced. The reason, of course, for such an occurrence is thermal stratification of the lakes in early spring and summer. Actual measurements of temperature and dissolved oxygen in deep lakes have indicated that the temperature varies from $20^{\circ} \mathrm{C}$ at the surface to $4^{\circ}$ to $10^{\circ} \mathrm{C}$ at depths between $15 \mathrm{~m}$ to $20 \mathrm{~m}$. The oxygen levels drop from $10 \mathrm{mg} / \mathrm{L}$ in the top layers to 0 to $5 \mathrm{mg} / \mathrm{I}$ at depths approximately $15 \mathrm{~m}$ from the top. At such low levels of dissolved oxygen in water, the survival of marine life is endangered and the resulting destruction of marine life causes foul odours and other environmental problems.

Such stratification is not confined only to deep natural lakes and harbours. Water discharged from the base of man-made dams and reservoirs to the open rivers often exhibit very low levels of dissolved oxygen and consequently damage plant and marine life. Other examples of stratification occur with miscible fluids with a density gradient e.g. in the storage of oils prior to their blending. 
Both the examples described above present a mixing problem. In the case of stratification of lakes, a sufficient amount of oxygen is available in the top layers of water and it needs only to be transported to the oxygendeficient layers down below. In other words, the thermocline needs to be destabilised. Blending of oils is generally done in large tanks (diameters range from $25 \mathrm{~m}$ to $50 \mathrm{~m}$ ). which are often submerged in the ground, because of which the installation of mixing equipment is cumbersome and expensive.

1.2 CONVENTIONAL APPROACHES TO THE PROBLEM: Generally three different devices of mixing are used for above mentioned problems; impellers, jets and air bubbling (diffusors). It may be emphasized here that not all three devices may be applicable for one single mixing problem and the choice will depend upon the given problem. Air bubbling for example is not used in oil tanks, because of the inflammable vapour problem.

Impellers and jets are generally used for oil-blending. Fossett (1) gives an excellent description of mixing induced by inclined jets in blending tanks. Other authors $(2,3,4)$ suggest the use of side-entering propeller mixers for blending problems. Based on blending experiments conducted in an 80,000-barrel tank, Rushton (2) found that the mixing performance, in terms of mixing time and the actual amount of energy expended, was better with the side-entering impellers ( 2 hrs, $1.09 \times 10^{8} \mathrm{~J}$ ) than was the case with the 
inclined jets ( $\left.9 \mathrm{hrs}, 3.73 \times 10^{8} \mathrm{~J}\right)$.

These authors, while evaluating impellers and jets, made no mention of the enormous costs involved in installation, maintenance and possible replacement of these devices. The amount of energy expended, though decreased considerably in the case of the side-entering propeller mixers, may still be substantially higher when compared to the minimum possible mixing energy required to mix stratified systems completely. Such considerations will be discussed in subsequent chapters.

In the case of destratification of lakes and harbours, impellers and jets are impractical and employment of diffusors is a rational alternative. A long polyurethene tube with longitudinal slots is spread along the bottom surface of a lake and air is forced through these slots. The rising air bubbles transport oxygen to the oxygen-deficient layers and also cause destabilisation of the thermocline. Such a device has been tested by the Ontario Ministry of Environment since 1975 (5) for the destabilisation of thermocline in Hamilton Harbour. The problems encountered with this device are the laying of long narrow plastic tubes, the possibility of these tubes being ripped apart by passing boats and ships, and the securing of the tubes.

1.3 Applications of vortex rings: As an alternative to the 
conventional methods of mixing described briefly above, an unique method of transporting a given mass of a fluid either upwards or downwards has been developed in this project for mixing purposes. Ring vortices provide an extremely efficient means of transporting one fluid through another. The production of ring vortices requires no moving parts and hence maintenance costs can be reduced. Ring vortices have an excellent characteristic of being able to penetrate through large distances without being deformed or broken. Vortex generators can be easily mounted on the top of blending tanks, and may be competitive with the installation costs of motor-driven propellers. In the case of destratification of lakes, the vortex generator can be placed on a barge, which, of course, can be moved to that area of the lake where destratification is urgently needed. Alternatively a number of vortex generators can be placed on different barges located in strategic positions. The laying of diffusor tubes is extremely cumbersome and is avoided if the vortex ring technique is used. Finally, the vortex generators are simple and may prove to be inexpensive and cheaper to operate.

1.4 HISTORY OF VORTEX RINGS: The existence of ring vortices has been known to mankind for thousands of years. American Indians have used them for communication and most smokers have at least attempted to form them. In the laboratory, these rings can be formed by two controlled methods: 1) by impulsively ejecting a puff of fluid (gas or liquid) from a circular 
aperture, and 2) by allowing a single drop of a liquid to fall from a height of a few $\mathrm{mm}$ into a pool of the same liquid (6).

It was Reynolds (7) who for the first time in 1876 demonstrated the formation of vortex rings in water at a $19 \mathrm{~mm}$ diameter orifice. The rings had a range of $6 \mathrm{~m}$ and their initial velocities were of the order of $2 \mathrm{~m} / \mathrm{s}$. Surprisingly, chemical engineers showed very little interest in finding applications for ring vortices. Most of the published work $(8,9,10,11,12,13)$ on the formation and hydrodynamics of the rings has concerned rings which were far too weak to be used for industrial applications. The velocities were up to $2 \mathrm{~cm} / \mathrm{s}$ and the range barely $50 \mathrm{~cm}$ or so. A team of scientists working under Dr. P. J. Baker at the laboratories of the British Hydromechanics Research Association at Cranfield has developed "Vortical Chimneys" to disperse industrial smokestack effluents by means of vortex rings (14,15). Kendig (16) provides an interesting survey of possible applications of vortex rings e.g. artificial formation of clouds by throwing up silver iodide particles into the atmosphere with the help of air ring vortices, destruction of the large turbulent wingtip vortices formed in air during take-off of large aeroplanes by air ring vortices fired from the ground, and oxygenation of deep waters behind large dams by employing vortex rings composed of aerated surface water. 
(17) are perhaps the first to have demonstrated the formation of ring vortices in water, which are powerful enough to be used for mixing applications. The velocities of such rings were given as approximately $2 \mathrm{~m} / \mathrm{s}$. Unpublished data from 1975 reported in this paper (17) quotes ranges up to $18 \mathrm{~m}$ from a $6.35 \mathrm{~cm}$ orifice. The orifice diameters varied from $2.54 \mathrm{~cm}$ to $6.35 \mathrm{~cm}$. These authors also concluded that the initial velocity of the vortices was in general one-half of the velocity of flow through the orifice ( see Chapter 3.3).

To use vortex rings for mixing fluids, it is required that the rings remain stable and that they can penetrate long distances without losing their form. In other words, if a ring is formed at the orifice, it must continue to travel appreciable distances without losing much of its momentum. Thus, if the initial momentum of the ring at the orifice is $I_{o}$ and $I_{d}$ is the momentum at a certain distance d from the orifice, then the ratio of $I_{d} / I_{0}$ will be a measure of the stability of a vortex ring. If the ratio is unity, the vortex ring is quite stable because it conserved its momentum over a distance d. This definition, however, gives no information as to what the distance d should be over which momentum is to be conserved. In reality, once a vortex is formed, it must remain stable, at least over a infinitively small distance travelled. Therefore, the definition of stability of a ring vortex is arbitrary and it refers to the conservation of momentum over a desired distance d travelled. Baird et al (17) found that the ratio of $I_{d} / I_{0}$ was unity (maximum stability) 
over a distance of $60 \mathrm{~cm}$ when the volume of fluid displaced through the orifice did not exceed $0.5 \pi \mathrm{d}_{0}^{3}$ (see chapter 3.3 ).

1.5 OBJECTIVE: It was mentioned earlier that during summer months a thermocline exists in deep lakes and that due to a lack of oxygen in deeper layers of water the marine life is endangered and the oxidation of organics is inhibited. Such anaerobic conditions deteriorate the water quality. Also, if two or more oils having different densities are slowly poured into a tank, they will exhibit quite sharp "interfaces", depending upon their densities. Both of these situations have one thing in common, stratification of fluids. In the case of stratification of lakes abundance of oxygen is available in the upper layers of water, and it only needs to be sent down below, whereas for blending of oils at least enough mixing energy must be supplied to overcome the potential energy barrier due to density difference.

The main objective of this work is to compare the theoretical energy required to mix miscible fluids separated by a density difference with the actual amount of energy that needs to be dissipated by ring vortices in order to mix such systems completely. In other words, the efficiency of mixing in such systems by means of ring vortices as a source of mixing energy, is to be determined。 
Figure 1

Schematic experimental arrangement for stratified fluids mixing with ring vortices.

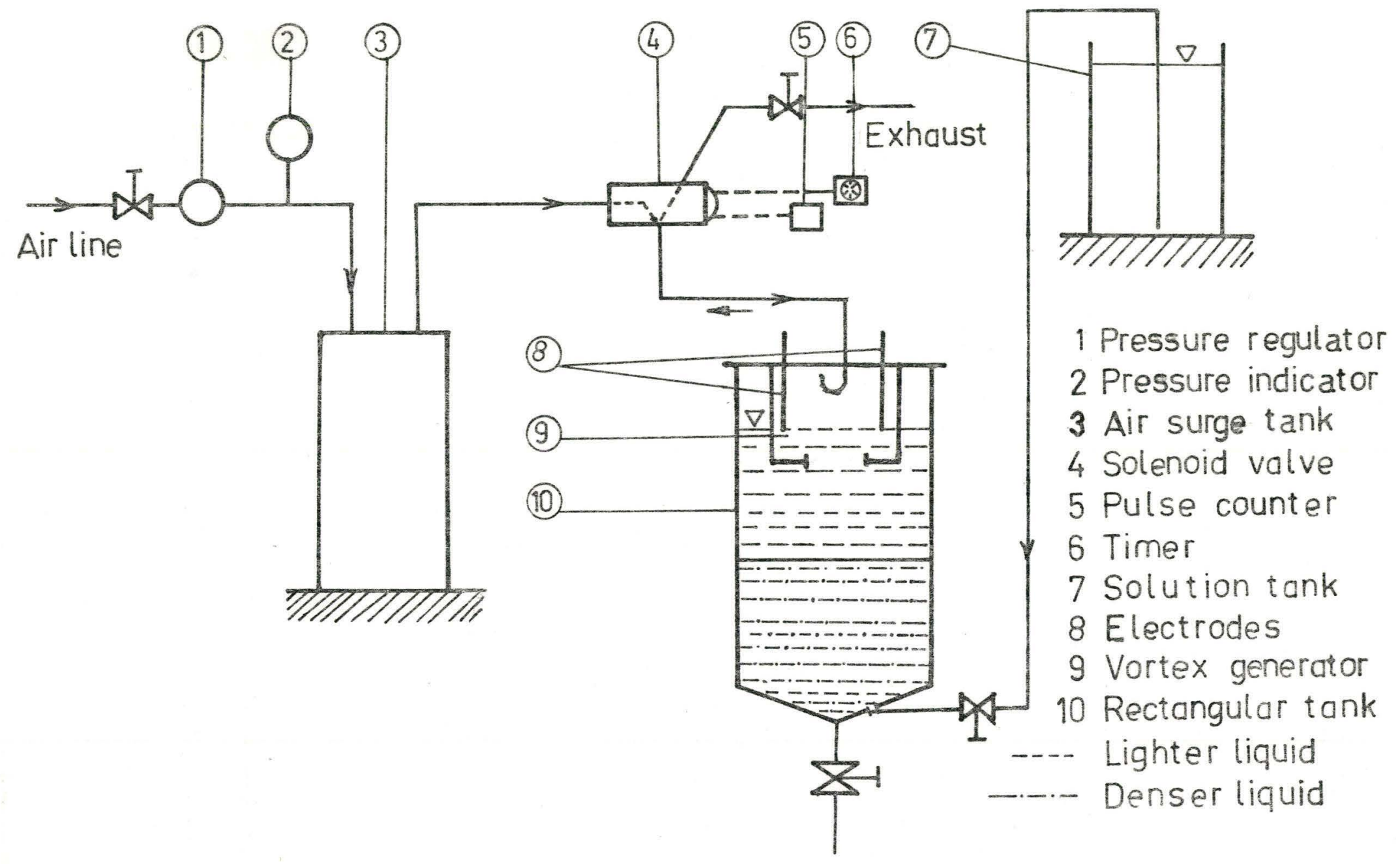




\section{CHAPTER 2}

\section{EXPERIMENTAL APPARATUS AND PROCEDURE}

2.1 VORTEX GENERATOR AND TEST TANK: Figure 1 shows the experimental arrangement for the mixing of miscible fluids separated by a density difference with the help of ring vortices. Baird et al (17) produced stable rings at orifices of diameter 2.54 to $6.35 \mathrm{~cm}$ by impulsively injecting a specific amount of air into the vortex generator, which consisted of a perspex cylindrical chamber of height $305 \mathrm{~mm}$ and overall diameter $178 \mathrm{~mm}$. The cylinder was closed at the bottom end and the orifice was mounted on the other end. The generator was situated at the bottom of the test tank with its closed end touching the bottom of the test tank and projected vortices upwards through the orifice.

In the present arrangement, the generator is placed at the top of the tank as shown in Figure 1, and the vortices are projected downwards. The principle of generation of a vortex ring is the same as in the work of Baird et al (17). A controlled amount of air was supplied impulsively to the vortex generator from the air reservoir (3 in Figure 1) at constant pressure, through a timed solenoid valve (4 in Figure 1). Injections times could be varied from $0.05 \mathrm{~s}$ upwards. The injected air entered the annular space through a "goose-neck" of copper tubing so that it impinged on the upper wall of the vortex generator 
rather than on the liquid surface. Vortex formation took place at a $6.35 \mathrm{~cm}$ orifice in all the present experiments. After the vortex ring was formed, the injected air was expelled slowly from the vortex chamber through an exhaust valve, which was, however, automatically disconnected by the solenoid valve during the air injection period. The water level which had been depressed during each air injection returned slowly to its original level after the air was expelled. The timer controlled the air injection and air expulsion time, the later being normally in the order of $20 \mathrm{~s}$.

The volume $\Delta V$ of air injected is an important parameter for determining the velocities of vortex rings, and it was measured directly from the change in water level in the generator ( 9 in Figure 1). Because the depression of water level took place within a very short time interval ( generally.05 s), a simple measurement by eye was not very accurate. Two different measuring techniques were employed for $\Delta V$ measurements : 1) The exhaust valve was shut so that during the period "off" ( injected air released to the atmosphere) the air was not released to the atmosphere and consequently the water level remained depressed. As the next air injection took place, the water escaped from the orifice in the form of vortex ring, but the injected air would remain into the vortex generator. Generally three successive vortices were formed and the initial and final levels of the water were noted. From the difference of water levels divided by the number of vortices formed, the $\Delta V$ per 
vortex was calculated. Unfortunately, this technique could only be used after the experiment was finished and these measurements would not detect any variations in $\Delta V$ during the experiments. 2) Two copper electrodes were inserted on either side of the vortex generator's top lid (8 in Figure 1). One of these electrodes was connected to a battery and an ammeter in series. Initially the electrode was adjusted such that its lower end just touched the surface of the water inside the vortex generator. During vortex ring formation the water level was depressed and the electric circuit was broken and hence no current passed through the ammeter. The electrode was then moved downwards until the electric circuit was just completed when the water level was at its minimum inside the vortex generator (after ring formation). The difference between the two submergences of the electrode gave the measured decrease in water level during vortex generation and consequently the volume of water displaced or air injected. The second electrode, when switched into the circuit, facilitated the $\Delta \mathrm{V}$ measurement on the other side of the vortex generator. The arithmetic mean of these two measurements provided a good measure of $\Delta \mathrm{V}$.

2.2 STRATIFICATION PROCEDURE: Sodium chloride solution was used as the heavier fluid and ordinary tap water was used as the lighter fluid. The rectangular tank was first filled with tap water up to a desired level. A measured quantity of $1 \mathrm{~N} \mathrm{HCl}$ ( $100 \mathrm{cc}$ ) was mixed with this water. When the water was quite 
calm, the NaCl-solution was gradually siphoned from the solution supply tank ( 7 in Figure 1) to the rectangular experimental tank through a very small circular opening (effective cross section $4 \mathrm{~mm}^{2}$ ) situated at the bottom of the experimental tank. The flow was effected by gravity only. The connecting tube was of $1.25 \mathrm{~cm}$ diameter. The added NaCl-solution contained a measured quantity of $1 \mathrm{~N} \mathrm{NaOH}$ ( $90 \mathrm{cc}$ ) and a small trace of phenolpthlein, thus making the solution pink in colour. The inflow rate was kept very low by pinching the connecting tube until a certain quantity of solution was transferred from the solution tank to the experimental tank. This precaution ensured the formation of a stable "interface" by minimising the penetration of incoming fluid jet. Once a certain depth of heavier fluid was established, ( with the "interface" well above the position of the orifice) the flow was increased by releasing the pinching of the connecting tube. This procedure produced a razor sharp interface. One could see the colourless lighter fluid in a distinct layer above the pink colour of the denser fluid. The average flow rate of denser fluid during the latter stages of the filling process was measured to be approximately $1.5 \mathrm{~L} / \mathrm{min}$.

2.3 DEGREE OF MIXING : The mixing or blending of two fluids requires that some definitive criterion be prescribed, in order to establish whether or not the mixing is complete. 
For example one may measure the density at different points in a mixing-vessel while mixing is proceeding and consider the mixing complete when measured densities at these points are the same or fall within given limits. Some of the other characteristics used in mixing operation are pH, colour, electric conductivity, concentration and refractive index. Absolute mixing implies homogeneity to the molecular level. To attain such mixing by mechanical means is very difficult because the scale of mixing decreases approximately exponentially with mixing time. For this reason, degree of mixing is usually defined as the desired uniformity of composition in a finished mix or blend. It is absolutely necessary that the degree of mixing and the employed characteristic are stated for each finished mix or blend. In the above example, the degree of mixing is given by the tolerance within which the measured densities must fall.

2.4 ACID/BASE/INDICATOR: The acid/base titration is an useful visual technique to study mixing times. The mixing equipment is started after the appropriate chemicals have been added to the mixing components. The appearance or disappearance of a particular colour defines the termination of mixing. The time elapsed gives the mixing time. The degree of mixing which is attained at this instant cannot be easily defined mathematically but the method is more complete and more stringent than any known method of analysing samples and establishing a standard deviation. This technique was first employed by Fox and Gex(18), in order to measure the time for complete mixing in an 
impeller-agitated tank.

In this particular study, mixing was considered complete when the pinkish alkaline heavier fluid was completely decolourised by the incoming acid contained in the lighter fluid, which, of course, was transported with the help of ring vortices into the heavier fluid. The criterion for degree of mixing was an $8 \%$ excess of the acid in the mix than was required by the stoichiometric consideration. The percentage of excess acid was maintained constant in all experiments because a change in the amount of excess acid will produce a different criterion of mixing. The uniformity of components in the mix will increase by decreasing the excess acid and vice versa. The percentage of excess acid was arbitrarily chosen. It is recommended that the experiments should not be conducted without the excess of the appropriate chemical because this would require absolute mixing as described in 2.3 .

2.5 EXPERIMENTAL PROCEDURE: The solution tank contained $40 \mathrm{I}$ of solution of desired density. Dissolved into it were $90 \mathrm{~mL}$ of $1 \mathrm{~N} \mathrm{NaOH}$ solution and a trace of phenolphthalein. The rectangular tank was first filled with $80 \mathrm{~L}$ of tap water and $100 \mathrm{~mL}$ of $1 \mathrm{~N}$ HCL was poured into it*. From the solution tank, the heavier liquid of given density was gradually and cautiously transferred into the bottom part of the experimental

*The acid and base concentrations used here exceeded the critical value of $5 \times 10^{-4} \mathrm{~N}$ above which Fox and Gex (18) have found that measured mixing time is independent of the concentrations added. 
tank as described in 2.2. The volume transferred was always $38 \mathrm{I}$ except in one series of experiments to be discussed later on. The desired air pressure and the vortex formation time were set and the experiment started. The number of vortices required to decolorise the formerly pinkish colour of the heavier liquid were recorded on a pulse counter. The amount of air injected per vortex was measured by both the methods described earlier. The time interval for injection of air through the solenoid into the vortex generator was measured by an oscillograph ( Hewlett-Packard, type 141A) connected to the solenoid timer. The interval between vortex "firings" was maintained long enough (generally $20 \mathrm{~s}$ ) to allow the fluid to calm down after the impact of each ring and to permit the water level in the vortex generator to return to its original level. This interval was raised up to $50 \mathrm{~s}$ when the experiments were conducted at higher pressures and longer formation times.

2.6 RANGES OF VARIABLES STUDIED: Four independent variables were studied; vortex formation time, air pressure or operating pressure, density of the heavier fluid, and the fraction of volume occupied by the denser Iiquid ( $\left.t_{i}, p, \rho_{d}, \phi\right)$. The orifice diameter, which was also an independent variable, was always kept constant at $6.35 \mathrm{~cm}$. In each case the dependent variable $\mathrm{E}_{a}$, the amount of required energy for terminal mixing, was obtained by counting the required number of vortices and relating them to the energy associated with each vortex. Energy calculations for vortices are discussed in chapter 3. 
Table 1 shows the range of variables studied. In each set of experiments only one independent variable was changed. Thus, there were four sets of experiment.

Table No.1 Range of Variables Studied

Variable

$\mathrm{p}$

$t_{i}$

$\varnothing$

$\rho$
Minimum

$55.16 \mathrm{kPa}$

$0.05 \mathrm{~s}$

0.178

$1.02 .66 \mathrm{gm} / \mathrm{cm}^{3}$
Maximum

$103.41 \mathrm{kPa}$

$0.18 \mathrm{~s}$

0.714

$1.1477 \mathrm{gm} / \mathrm{cm}^{3}$

There were two different kinds of constraints associated with the study of variables; physical constraints and limitations of the given apparatus.

Physical Constraints:

1 The heavier liquid density could only be increased up to its saturation point and from the practicality point of view only $70 \%$ of saturation point was tried.

2 The upper limit of vortex formation time was arrived at by trial and error only. It was found that formation times greater than approximately 0.20 seconds did not produce stable rings and this will be discussed in chapter 5 .

3 "Interface"was not distinctly sharp for densities below $1.012 \mathrm{gm} / \mathrm{cm}^{3}$. 
4 Vortex formation began to deteriorate at pressures below $55.16 \mathrm{kPa}$.

Limitations of Given Apparatus:

1 The upper limit of air pressure, $103.41 \mathrm{kPa}$, was due to the avaiable pressure gauge and to safety considerations.

2 The maximum possible interval of 1 min (Timer) between the vortex firings was insufficient to permit the return of large volumes of liquid displaced from the vortex generator at pressures higher than $103.41 \mathrm{kPa}$.

3 The height of the available experimental tank limited the depths of the two fluids employed. 
CHAPTER 3

\section{ENERGY RELATIONSHIPS}

3.1 THEORETICAL MIXING ENERGY REQUIRED FOR A STRATIFIED FLUID SYSTEM: Consider an initially stratified fluid system with a sharp interface, in which the bottom layer has a higher density than the fluid above it as shown in Figure 2. Both layers have their respective centres of gravity $\left(G_{1}, G_{d}\right)$, and the liquid as a whole has its centre of gravity at an intermediate point $G^{\prime}$. If such a stratified fluid system is mixed completely, its centre of gravity will be moved upwards (G") provided no volume change has taken place. The change in potential energy of the system gives the theoretical energy •

BEFORE MIXING

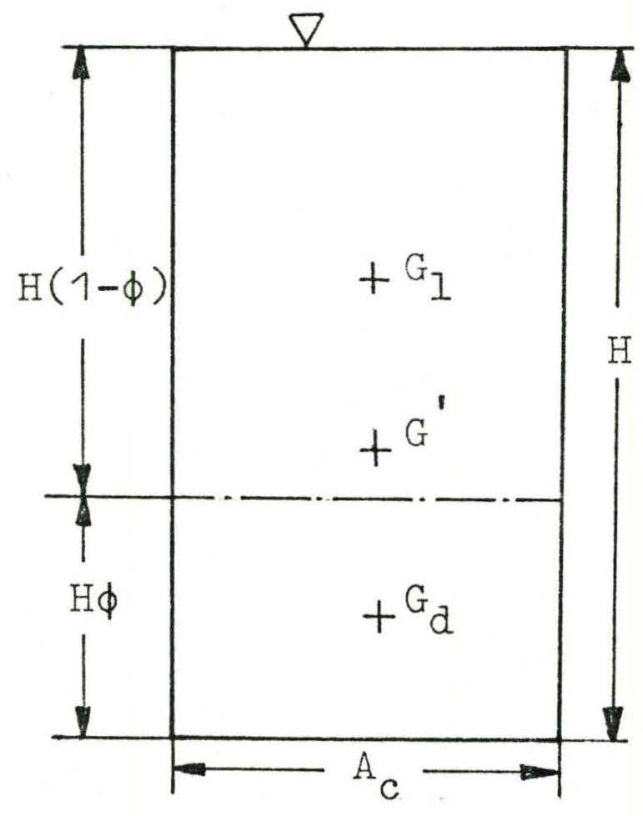

AFTER MIXING

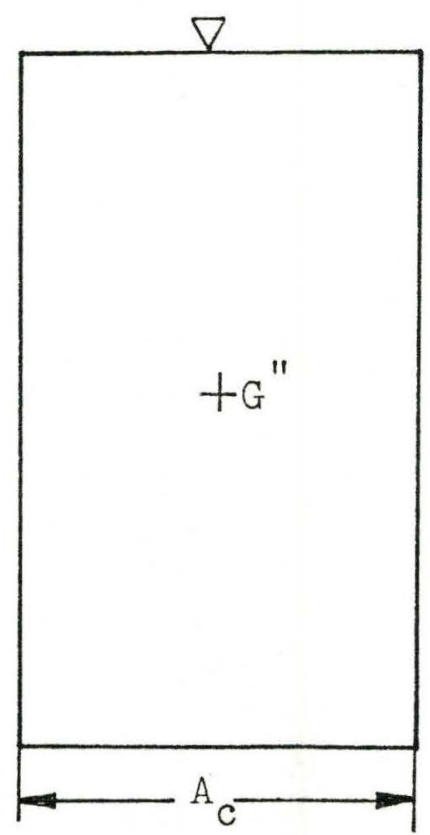

Figure No.2 
a)

Height of centre of gravity of denser liquid

$=\mathrm{H} \phi / 2$

Therefore,

(P.E.) $\mathrm{d}$

$=\quad \mathrm{A}_{\mathrm{c}} \mathrm{H}^{2} \mathrm{~g} \mathrm{~d}_{\mathrm{d}} \phi^{2} / 2$

b) Iight fluid mass

$$
=\quad \rho_{1} A_{c} H(1-\phi)
$$

Height of centre of gravity of lighter liquid

$$
=H(1+\phi) / 2
$$

Therefore,

$$
\text { (P.E.) }{ }_{1}
$$$$
=\quad A_{C} H^{2} g \rho_{1}\left(1-\phi^{2}\right) / 2
$$

Now consider "well mixed" liquid, and assume that the total liquid height is unchanged ( no volume change after mixing ).

Mass of liquid:

$$
\mathrm{A}_{\mathrm{c}} \mathrm{H \phi \rho} \mathrm{d}+\mathrm{A}_{\mathrm{c}} \mathrm{H}(1-\phi) \rho_{1}
$$

Centre of gravity:

$\mathrm{H} / 2$

P.E. of the mixed Iiquid is

$$
\text { (P.E. })_{\operatorname{mix}} \quad=\quad \mathrm{A}_{\mathrm{c}} \mathrm{H}^{2} \mathrm{~g}\left(\phi \rho_{\mathrm{d}}+(1-\phi) \rho_{1}\right) / 2
$$


Change in system's P.E. due to mixing:

$$
\begin{aligned}
& \triangle_{\text {P.E. }}=(\text { P.E. })_{\operatorname{mix}}-(\text { P.E. })_{\mathrm{d}}-(\text { P.E. })_{1} \\
& \Delta_{\text {P.E. }} \quad=E_{t}=\left(\phi-\phi^{2}\right)\left(\rho_{\mathrm{d}}-\rho_{1}\right) \mathrm{A}_{\mathrm{c}} \mathrm{H}^{2} \mathrm{~g} / 2
\end{aligned}
$$

This equation gives the theoretical energy, $E_{t}$, required for mixing of two layers of liquid with different densities, neglecting all frictional effects and neglecting volume changes. As expected, the above equation gives a Zero energy requirement if the two fluids have the same density, e.g. If the fluid is all light or all heavy ( $\phi=$ o or 1$)$. For a given total volume of two given fluids, the potential energy requirement is greatest when 50 volume \% of each fluid is present. 
3.2 EFFICIENCY OF MIXING:

3.2.1 ENERGY EFFICIENCY: An expression describing the theoretical mixing energy $E_{t}$ for a stratified fluid system has been derived in chapter 3.1. Consider now that the system has been mixed completely by any given mixing mechanism; impellers, jets, diffusors or ring vortices. If the amount of energy used is $\mathrm{E}_{a}$, then the mixing efficiency is defined by :

$$
\varepsilon=E_{t} / E_{a}
$$

Wilson of the Shell Oil Company (4) discussed the blending of oils of different densities by in-tank impeller mixers. Figure 3 of this paper described the relationship between the initial specific gravity difference in the tank and the blending time. The theoretical mixing requirement is the same as was discussed in chapter 3.1. The following data were taken from Wilson's paper, in order to calculate mixing efficiency.

Mixing time

Initial specific gravity difference

Tank capacity

Tank area
50 Hours

$10^{\circ} \mathrm{API}$ or $50 \mathrm{~kg} / \mathrm{m}^{3}$

$80,000 \mathrm{bbl}$ or $9,536 \mathrm{~m}^{3}$

$884 m^{2}$ 
No. of mixers used

Assumptions :

Energy input:

Theoretical energy
:

$E_{t}=\underline{6.3 \times 10^{6}}$

J (using equation

(4))

Mixing

efficiency :

1) 25 HP Motor was 60\% loaded, i.e.

$15 \mathrm{HP}$ on the shaft

2) $\phi=0.5$

$$
\begin{aligned}
\mathrm{E}_{\mathrm{a}}=50 \times 15 & =750 \mathrm{HP}-\mathrm{hr} \\
& =560 \mathrm{~kW}-\mathrm{hr} \\
& =2 \times 10^{9} \mathrm{~J}
\end{aligned}
$$

$$
\varepsilon=E_{t} / E_{a}=\frac{6.3 \times 10^{6}}{2 \times 10^{9}}=\underline{0.3 \%}
$$

The following two additional examples have been taken from the literature as well, and as in the previous example, the efficiency of mixing is calculated.

Example No.2 Mixing tetraethyl lead (TEL) with gasoline in an 80,000-barrel tank by using a sideentering impeller mixer. The following data are taken from Rushton's Paper (2) 
Tank height

Tank area

Tank volume

No. of mixers
$11.9 \mathrm{~m}$

$1050.4 \mathrm{~m}^{2}$

$12478.7 \mathrm{~m}^{3}$

1

Concentration of TEI in denser phase $15.25 \mathrm{cc} / \mathrm{gal}$

Concentration of TEL in lighter phase

$0.35 \mathrm{cc} / \mathrm{gal}$

(Taken from

Final concentration of TEL after mixing complete

$1.70 \mathrm{cc} / \mathrm{gal}$

From TEL balance $\phi=0.091$

Assumption: Density difference $=20 \mathrm{~kg} / \mathrm{m}^{3}$ (Av. value)

$$
\begin{array}{ll}
E_{t}=1.2 \times 10^{6} \mathrm{~J} & \text { (calculated from } \mathrm{Eq} \cdot 4 \text { ) } \\
\mathrm{E}_{\mathrm{a}}=1.1 \times 10^{8} \mathrm{~J} & \text { (given) }
\end{array}
$$

Mixing efficiency $=E_{t} / E_{a}=1.1 \%$

Example No.3 Mixing of stratified water with side-

$$
\text { entering impeller mixer (3) }
$$

Tank diameter $\quad 6.1 \mathrm{~m}$

Tank height $\quad 6.1 \mathrm{~m}$

Volume of Iiquid $\quad 178.3 \mathrm{~m}^{3}$

Assumption : $\phi=0.09$

Theoretical energy

$$
\begin{array}{ll}
E_{t}=7 \times 10^{3} \mathrm{~J} & (\text { From Equation No.4) } \\
\mathrm{E}_{\mathrm{a}}=1.1 \times 10^{6} \mathrm{~J} & \begin{array}{l}
\text { (obtained from } \\
\text { Figure 6 }
\end{array}
\end{array}
$$

Efficiency $E_{t} / E_{a}=\underline{0.6 \%}$

The calculated efficiencies are discussed in chapter 5. 
3.2.2 VOLUMETRIC MIXING EFFICIENCY: Consider Figure 2) in which miscible fluid layers are separated due to a density difference. It could be assumed that mixing was complete as soon as the last drop of lighter fluid was transported into heavier fluid, irrespective of energy considerations. This assumption would be reasonable if enough energy was supplied during the volume transfer process, e.g. if one fluid was poured into the other from a great height. Attention is now drawn to Figure 1) where the same volumes of the two fluids are separated by an interface. In this instance the mixing is accomplished by sending a number of ring vortices of lighter fluid into the heavier fluid. Will the volume of the lighter fluid sent down in vortex rings before mixing is complete, correspond to the volume of light fluid initially present?

\section{A ring vortex is a mass of fluid} rotating about a circular axis. Upon its formation at the orifice, it travels with a specific velocity and momentum depending upon certain parameters discussed in chapter 3.3. A downward moving vortex ring strikes and usually penetrates the sharp interface causing it to deflect. After the point of maximum deflection of the interface is reached, the buoyancy forces cause the interface to recoil, thus ejecting denser fluid into the upper layer. This denser fluid then mixes with the fluid above. Also, during its motion a great 
deal of turbulence is created in the vicinity of the path of the ring, and this contributes to mixing. Finally, the ring reaches the bottom of the tank and is dissipated thereby converting a part of its kinetic energy into mixing energy. It is therefore obvious that the volume of lighter liquid needed to effect complete mixing will be less than its original volume as was the case in mixing by pouring only.

Based on this discussion, one can define the volumetric efficiency of mixing effected by ring vortices in a stratified fluid system, and it is as follows :

$$
\varepsilon_{v}=V_{t} / V_{a}=\frac{(1-\phi) V_{t o t}}{N x \Delta V}
$$

where $V_{t}$ is simply the original volume of the lighter fluid, and $\mathrm{V}_{\mathrm{a}}$ the actual volume of lighter fluid used to effect complete mixing. This efficiency will increase as more energy is added to the system per unit of fluid transported.

3.3 ENERGY AVAILABLE IN A VORTEX RING : Baird et al (17) studied the effect of formation conditions on the velocity and momentum of a vortex ring. It was established that the propagation velocity of a vortex ring could be estimated as one-half of the forming jet velocity, and the mass of 
the vortex ring as twice that of the jet. Further, it was assumed that the volume of air injected was equal to the volume of liquid displaced through the orifice. The mass, velocity, momentum, and kinetic energy of a vortex ring in the absence of losses were then given by :

Mass of the vortex ring: $\mathrm{m}_{\mathrm{V}}=2 \rho \Delta \mathrm{V}$

Vortex velocity :

$$
u_{v}=\Delta v / 2 \pi R_{0}^{2} t_{i}
$$

Momentum:

$$
\mathrm{M}_{\mathrm{V}}=2 \rho \Delta \mathrm{V} \mathrm{u}_{\mathrm{V}}
$$

Kinetic energy : $\quad \mathrm{E}_{\mathrm{V}}=2 \rho \Delta \mathrm{Vu}_{\mathrm{v}}{ }^{2}$

Equation No.10 gives both the translational and rotational kinetic energies contained in a vortex ring, and this equation has been used in this work to calculate the energy of a vortex ring. The quantities, volume of air injected $\mathrm{AV}$ and air injection time or vortex formation $t_{i m e} t_{i}$, were measured as described in sections 2.1 and 2.5. The kinetic energy, calculated from Equations 7 and 8, will only be the translational kinetic energy of the vortex ring.

*Equation (10) can be obtained from the purely translational kinetic energy of the jet passing through the orifice, having mass $\rho \Delta \mathrm{V}$ and velocity $2 \mathrm{u}_{\mathrm{v}}$. 


\section{CHAPTER 4}

\section{RESULTS}

The results are referenced in Table No. 2 below:

Table No.2

Scheme of experiments on stratified liquid mixing:

Independent variable

Air pressure

Density of heavy liquid

Vortex formation time

Liquid volume ratio $\phi$
Table No.

3

4

5

6
Figure No.

3

$4,4 a$

5

6

4.1 UNMIXED LIQUID: It was observed during the course of experiments that the volume of lighter liquid above the orifice but not contained inside the vortex generator did not get mixed at all. This unmixed volume was calculated to be $6 \mathrm{~L}$ and remained constant for each experiment because the total volume in each case was maintained constant. It was documented by adding $100 \mathrm{~mL}$ of $1 \mathrm{~N} \mathrm{NaOH}$ and a trace of phenolphthalein into the denser fluid but no acid into the lighter fluid. After vigorous mixing with ring vortices it was observed that the entire liquid became pink except the volume mentioned above. Obviously, these $6 \mathrm{I}$ of unmixed volume were deducted from the $80 \mathrm{I}$ of lighter liquid used in each experiment. 
CHAPTER 5

DISCUSSION

5.1 DESIGN OF VORTEX GENERATOR : For the formation of a ring vortex, almost all previous authors $(6,8,9,11,13,17)$ had used the principle of impulsively ejecting a puff of fluid (gas or liquid) from a circular sharp edged orifice. However, the method of ejecting the fluid in a very short period of time had differed from author to author. Maxworthy (8) used a piston inside a cylinder to eject the fluid impulsively. The piston was driven by a cam/cam-follower system which was in turn driven by the output from a motor and a variablespeed gear box through a magnetic clutch. Linden (13) used a rubber diaphragm mounted on the roof of the cylinder and by striking this diaphragm an impulse was imparted to the fluid in the cylindrical chamber causing the formation of a ring vortex at the orifice. Baird et al (17) used a solenoid valve which allowed a given volume of air to enter the cylinder impulsively and thereby caused the formation of a ring vortex at the orifice which was mounted at the bottom of a water tank.

\section{The impulse generation techniques of} the previous workers were satisfactory for scientific measurements but have some disadvantages when considered from the point of view of reliable, large scale applications. The 
vortex generator of Maxworthy could over a long period give a problem of jamming the piston inside the cylinder. Also the response from the motor to the piston was delayed. In the case of the vortex generator of Linden (13) the stretching of rubber diaphragm caused secondary vibrations into the fluid inside the cylinder, thus restricting the continuous use of the vortex generator. Apart from this mechanical operational problems, the rings produced were weak and became unstable after having travelled a distance of only $50 \mathrm{~cm}$ or so. The velocities produced were of the order of $2 \mathrm{~cm} / \mathrm{s}$. Such weak rings could not be used for mixing applications on an industrial scale.

Rings produced from Baird's technique were stable (range at least $3 \mathrm{~m}$, velocity $2 \mathrm{~m} / \mathrm{s}$ ) and the performance of his vortex generator was reliable in the sense that it had no moving parts and therefore could be used continuously. The original generator (17), however, produced rings which travelled vertically upwards. This author has used Baird's technique with the difference that the vortex generator has been mounted at the top and that it produces rings, which travel downwards. Another advantage of using the air injection technique is to be able to calculate the vortex velocity and momentum easily and accurately. Furthermore, the vortex generator can easily be placed over any tank and the primary energy source, compressed air,is usually available in industry. 
5.2 REPRODUCIBILITY OF EXPERIMENTAL RESULTS: Reproducibility in this work is considered reasonable. Two experiments conducted at the same operating condition never produced exactly the same result in terms of dependent variable (number of vortices required for complete mixing), the lack of reproducibility being caused mainly by non-uniform operation of the solenoid valve. Other secondary sources of error were incorrect measuring of the fluid volumes, stabilisation of operating pressure and some indeterminate mixing during transfer of the heavy fluid from the solution tank to the experimental tank. It was, however,observed that the secondary sources of error did not contribute much to the nonreproducibilty. To prevent these sources of error from having any appreciable effect on results, two or more experiments were conducted at each operating condition. A third experiment was carried out only when the results of the first two experiments differed by more than 10\%. In the majority of the cases three experiments were needed, and the three results were averaged.

5.3 COMPARISON OF ENERGY EFFICIENCY IN AN IMPELLER MIXER IN A VORTEX MIXER : The overall efficiency of the vortex mixer used to mix the stratified system is given in Tables 3 to 6 and varied from 9 to 30\%, depending upon the operating conditions (variation in $\rho, \phi, t_{i}$ and $p$ ). The energy efficiency has been calculated in section 3.2.1 for three different cases; blending of oils, blending tetraethyl lead with gasoline and 
mixing of hot and cold water. In each case, the fluids were initially separated by a density difference and a side-entering propeller mixer was used to mix these systems. The necessary data were obtained from the literature $(2,3,4)$. The calculated efficiencies were $0.3,1.1$ and $0.6 \%$ respectively. This indicates tentatively that the vortex mixer may have a higher utilisation of input energy, however, more experiments for the efficiency comparison are suggested.

5.4 EFFECT OF AIR PRESSURE: Figure 3 and Table 3 present the results of the first set of experiments, in which the operating pressure was varied and $t_{i}, \rho$, and $\phi$ were kept constant. The lower curve on Figure 3 relates the total energy used $\left(\mathrm{NxE}_{\mathrm{v}}\right)$ for complete mixing of the stratified fluid with variations in pressure. Also indicated here is the theoretical energy requirement according to Equation No.4. The energy efficiency tends to deteriorate with the increase in operating pressure. By increasing the pressure, a greater volume of water is displaced through the orifice and because the vortex formation time $t_{i}$ remains constant, both the velocity and momentum of the ring are increased. The mixing is, in fact, accomplished by three mechanisms. 1) The vortex ring strikes the interface, which is deflected to its maximum point of deflection and because of buoyancy it recoils thereby spilling a considerable volume of heavier liquid into lighter liquid above it and gets mixed. This mechanism has been suggested by Linden (13). 2) The vortex ring creates a considerable 
Figure No.3

Effect of pressure on performance
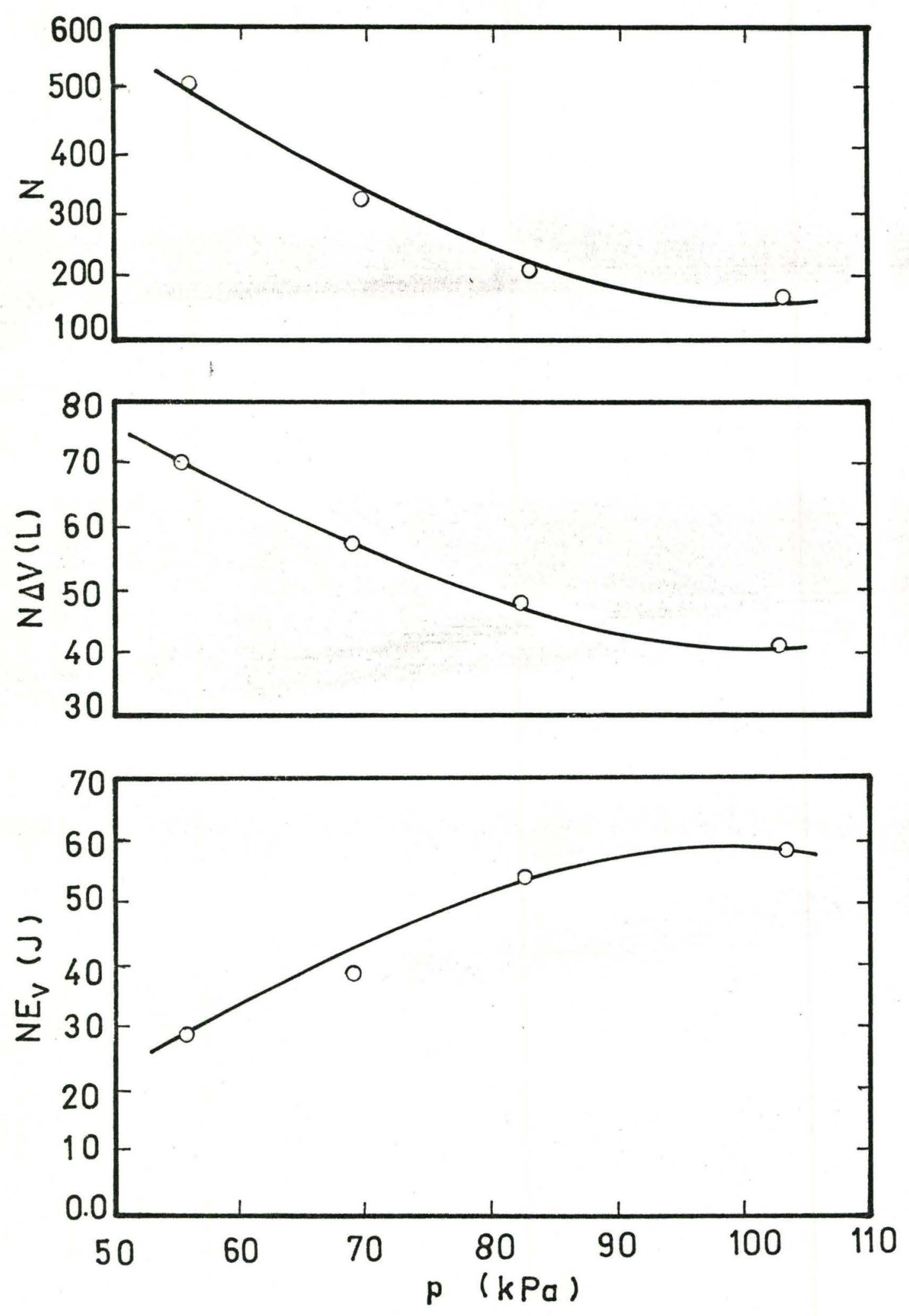
TABLE NO. 3

Effect of air pressure on performance.

\begin{tabular}{|c|c|c|c|c|c|c|c|c|}
\hline $\begin{array}{c}\mathrm{p} \\
\mathrm{kPa}\end{array}$ & $\begin{array}{r}\Delta V \\
(L)\end{array}$ & $\begin{array}{l}\text { Average } \\
\text { No.of } \\
\text { Vortices } \\
\text { N }\end{array}$ & $\begin{array}{l}\mathrm{E}_{\mathrm{V}} \\
\mathrm{J}\end{array}$ & $\begin{array}{c}\mathrm{V}_{\mathrm{a}} \\
\mathrm{Nx} \Delta \mathrm{V} \\
(\mathrm{L})\end{array}$ & $\begin{array}{c}\mathrm{E}_{\mathrm{a}} \\
\mathrm{NxE}_{\mathrm{v}} \\
\mathrm{J}\end{array}$ & $\begin{array}{c}\varepsilon \\
\mathrm{E}_{\mathrm{t}} / \mathrm{E}_{\mathrm{a}} \\
\%\end{array}$ & $\begin{array}{l}\varepsilon_{v} \\
v_{t} / V_{a}\end{array}$ & $\frac{u_{0} x t_{i}}{d_{0}}$ \\
\hline 55.2 & 0.139 & 505 & .054 & 70.19 & 27.27 & 19.28 & 1.05 & 0.7 \\
\hline 68.9 & 0.181 & 325 & .118 & 58.82 & 38.35 & 13.71 & 1.26 & 0.9 \\
\hline 82.7 & 0.239 & 201 & .272 & 48.04 & 54.67 & 9.62 & 1.54 & 1.2 \\
\hline 103.4 & 0.266 & 156 & .375 & 41.50 & 58.50 & 8.99 & 1.78 & 1.3 \\
\hline
\end{tabular}
$E_{t}=5.26 \mathrm{~J}$
Effective lighter fluid volume $V_{t}=74 \mathrm{~L}$
$\mathrm{V}_{\mathrm{d}}=38 \mathrm{~L}$
$\rho_{\mathrm{d}}=1.0412 \mathrm{gm} / \mathrm{cm}^{3}$
$A_{c}=0.1076 \mathrm{~m}^{2}$
$t_{i}=0.05 \mathrm{~s}$ 
amount of turbulence along its path of travel and thereby causes mixing. 3) Upon penetration to the bottom of the tank, the kinetic energy of the ring is dissipated and any light liquid remaining in the ring becomes mixed. Apart from these three mechanisms a negligible amount of mixing is also created by a secondary vortex ring which was seen to follow the principal vortex ring. The deterioration of efficiency with the increase in pressure can be explained to the effect that the majority of the vortex kinetic energy is lost upon impact at the bottom of the tank, because the kinetic energy increases with pressure and that more and more of this energy is lost in the impact which only mixes that portion of light liquid which is in the ring.

The middle curve in Figure 3 presents the volume of liquid sent down below to effect complete mixing as a function of pressure. The volumetric efficiency $\left(V_{t} /(N \Delta V)\right)$ tends to improve with pressure. As discussed above, the increase in pressure causes the increase in the mass of fluid contained in each vortex ring and in the energy per unit mass of fluid in the ring. The improvement in volumetric efficiency occurs because a) increase in turbulence along the ring's path causes more tank volume to $\operatorname{mix}, \mathrm{b})$ the increase in momentum produces more recoil volume to be mixed above with the lighter fluid and finally c) a greater volume of liquid contained in the vortex ring gets mixed at the bottom of the tank. All these 
effects occur at the cost of energy, thereby decreasing the energy efficiency and increasing the volumetric efficiency.

5.5 EFFECT OF LIQUID DENSITY : According to the theoretical energy equation (4), the $E_{t}$ is a function of $\phi$ and $\Delta P$. In the second set of experiments, $\phi, t_{i}$ and $p$ are constant (Figures 4, and $4 a$, Table 4). The function $E_{t}$ versus $\rho_{\mathrm{d}}$ from equation (4) is therefore a straight line passing through the origin, indicating that for no density difference, the theoretical energy is Zero. Above this function the actual energy used is shown in Figure 4 as a funtion of $\rho_{\mathrm{d}}$. The line through the data points is drawn parallel to the theoretical line and represents the data quite well. When this line is extrapolated to the value $\rho_{\mathrm{d}}=1$, it exhibits an intercept indicating that there is a specific amount of energy required, in order to mix a system of fluid without density difference. The presence of an intercept can be explained by the fact that all the energy contained in a vortex ring is lost upon impact with the bottom of the tank. The improvement in the energy efficiency with increasing density of the denser fluid is due to relatively less loss of energy during impact with the bottom and a higher degree of conversion of vortex kinetic energy into "mixing energy", i.e. the potential energy term derived in equation (4).

The volumetric efficiency $\left.V_{t} /(N \Delta V)\right)$

(see pigure 4a) tends todecrease with increase in density of the denser fluid. The interaction of a vortex ring with a 
Figure 4 .

Effect of denser fluid density on performance.

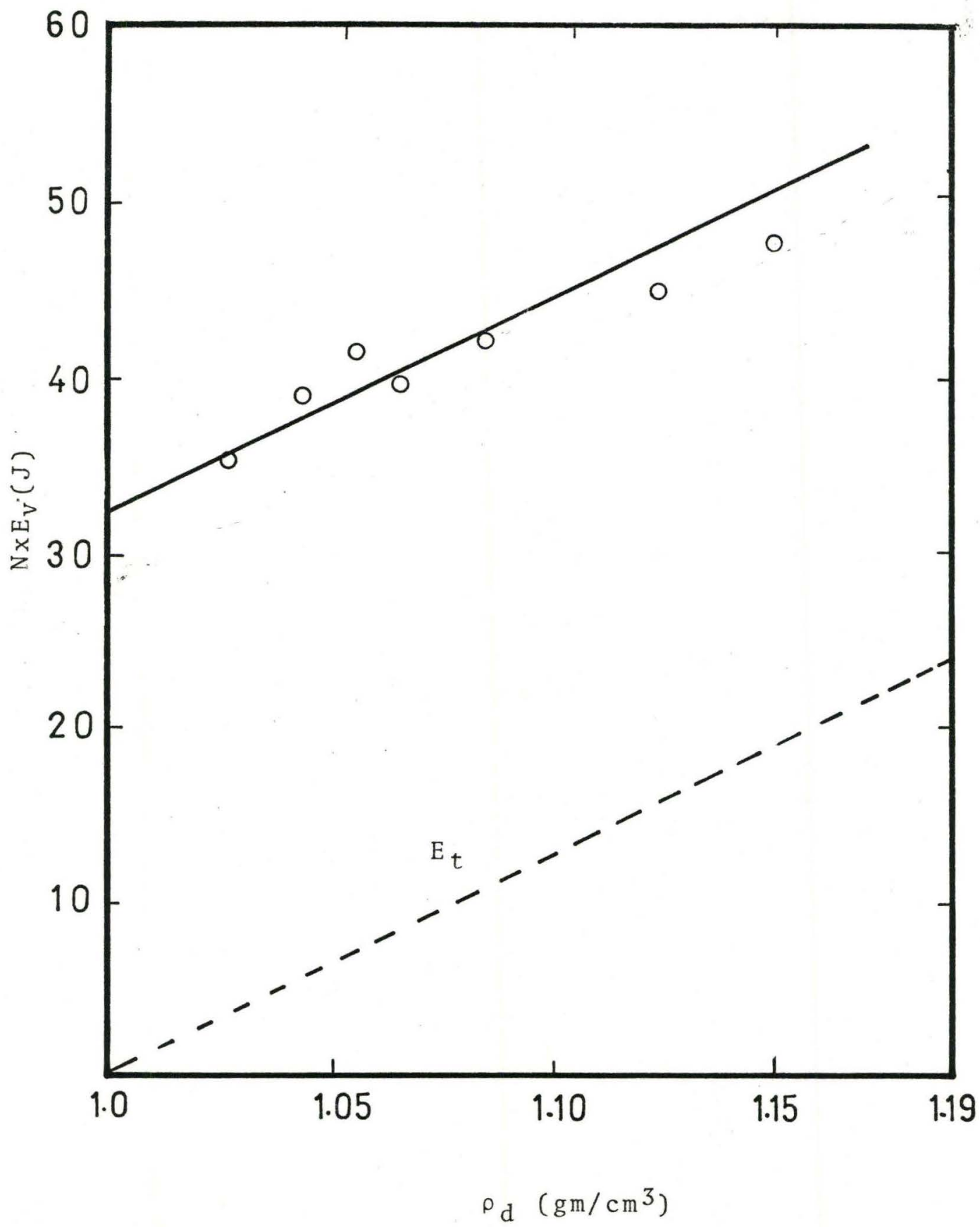


Figure $4 \mathrm{a}$.

Effect of denser fluid density on performance.
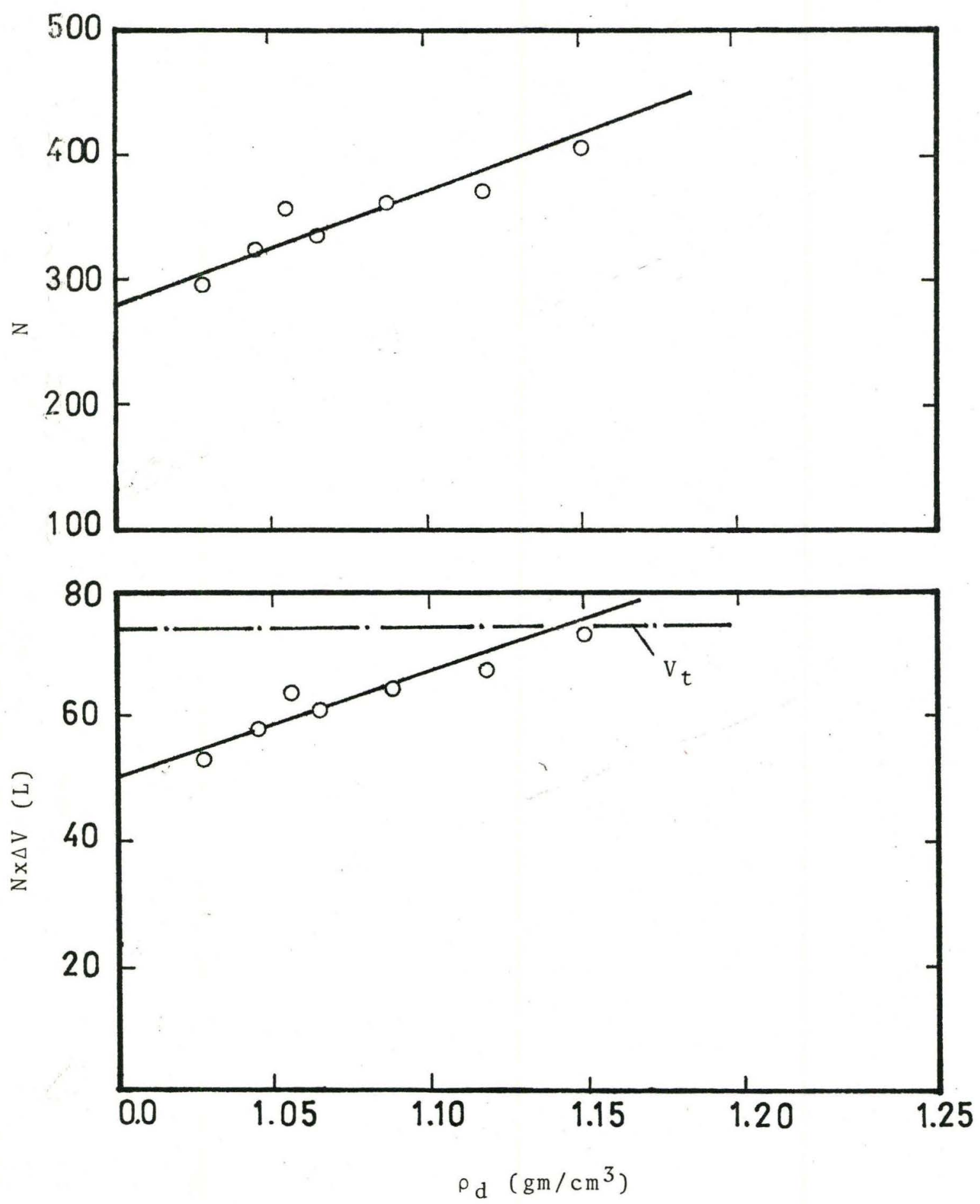
TABLE NO . 4

Effect of denser fluid density on performance.

\begin{tabular}{|c|c|c|c|c|c|c|}
\hline $\begin{array}{c}\rho_{\mathrm{d}} \\
\mathrm{gm} / \mathrm{cm}^{3}\end{array}$ & $\begin{array}{l}\text { Average } \\
\text { No.of } \\
\text { Vortices } \\
\text { Required } \\
\quad \text { N }\end{array}$ & $\begin{array}{c}\mathrm{E}_{\mathrm{a}} \\
\mathrm{NxE}_{\mathrm{v}} \\
(\mathrm{J})\end{array}$ & $\begin{array}{c}\mathrm{V}_{\mathrm{a}} \\
\mathrm{N} \times \Delta \mathrm{V} \\
{ }_{1} \mathrm{~L}\end{array}$ & $\begin{array}{l}E_{t} \\
(J)\end{array}$ & $\begin{array}{c}\varepsilon_{\mathrm{v}} \\
\mathrm{v}_{\mathrm{t}} / \mathrm{V}_{\mathrm{a}}\end{array}$ & $\begin{array}{c}\varepsilon \\
E_{t} / E_{a} \\
\%\end{array}$ \\
\hline 1.0266 & 294 & 34.79 & 53.21 & 3.39 & 1.39 & 9.74 \\
\hline 1.0412 & 325 & 38.35 & 58.83 & 5.26 & 1.26 & 13.71 \\
\hline 1.0558 & 357 & 42.13 & 64.62 & 7.12 & 1.15 & 16.90 \\
\hline 1.0632 & 334 & 39.41 & 60.45 & 8.07 & 1.22 & 20.47 \\
\hline 1.0855 & 357 & 42.13 & 64.62 & 10.92 & 1.14 & 25.92 \\
\hline 1.1160 & 365 & 43.07 & 66.07 & 14.25 & 1.12 & 33.08 \\
\hline 1.1477 & 404 & 47.67 & 73.12 & 14.66 & $1.0 \mathrm{I}$ & 30.75 \\
\hline
\end{tabular}

$\begin{aligned} \mathrm{p} & =68.9 \mathrm{kPa} \\ \mathrm{E}_{\mathrm{V}} & =0.118 \mathrm{~J} \\ \Delta \mathrm{V} & =0.181 \mathrm{~L}\end{aligned}$

Effective lighter fluid volume $V_{t}=74 \mathrm{~L}$ $\mathrm{t}_{\mathrm{i}}=0.05 \mathrm{~s}$

$\underline{u_{0} \times t_{i}}=0.9$ 
sharp density interface was investigated in the laboratory by Iinden (13). It was proposed that the volume rate of entrainment produced by the impact of a vortex ring with the interface was proportional to the cube of the Froude number. The Froude number of the flow was based on the density difference between the layers, the velocity of the ring perpendicular to the interface and the diameter of the ring. In this case, both the diameter and velocity of the rings are kept constant ( energy per unit vortex constant ). As the density difference increases, the Froude number decreases and the volume rate of entrainment across the interface decreases. The results indicated in Figure $4 \mathrm{a}$ are consistent* with the above explanation that the volumetric efficiency decreases with the increase in density difference, provided the energy per vortex is maintained constant.

5.6 EFFECT OF VORTEX FORMATION TIME: The lower curve in Figure 5 represents the function $E_{a}=f\left(t_{i}\right)$, other variables being constant. The energy efficiency first increases with $t_{i}$ reaching a maximum at $t_{i}=0.12 \mathrm{~s}(\varepsilon=18.28 \%)$. The increase in the efficiency is brought about by the slowing down of the vortex ring, so that majority of its kinetic energy is converted to the mixing energy ( potential energy) and that loss of energy due to collision with the bottom of the tank is

*The word "consistent" refers here only to the increase or decrease in ejected volume across the interface with Froude number. Whether the ejected volume in this case will follow the cubic relationship mentioned earlier is uncertain, and was not investigated. 
Figure 5 .
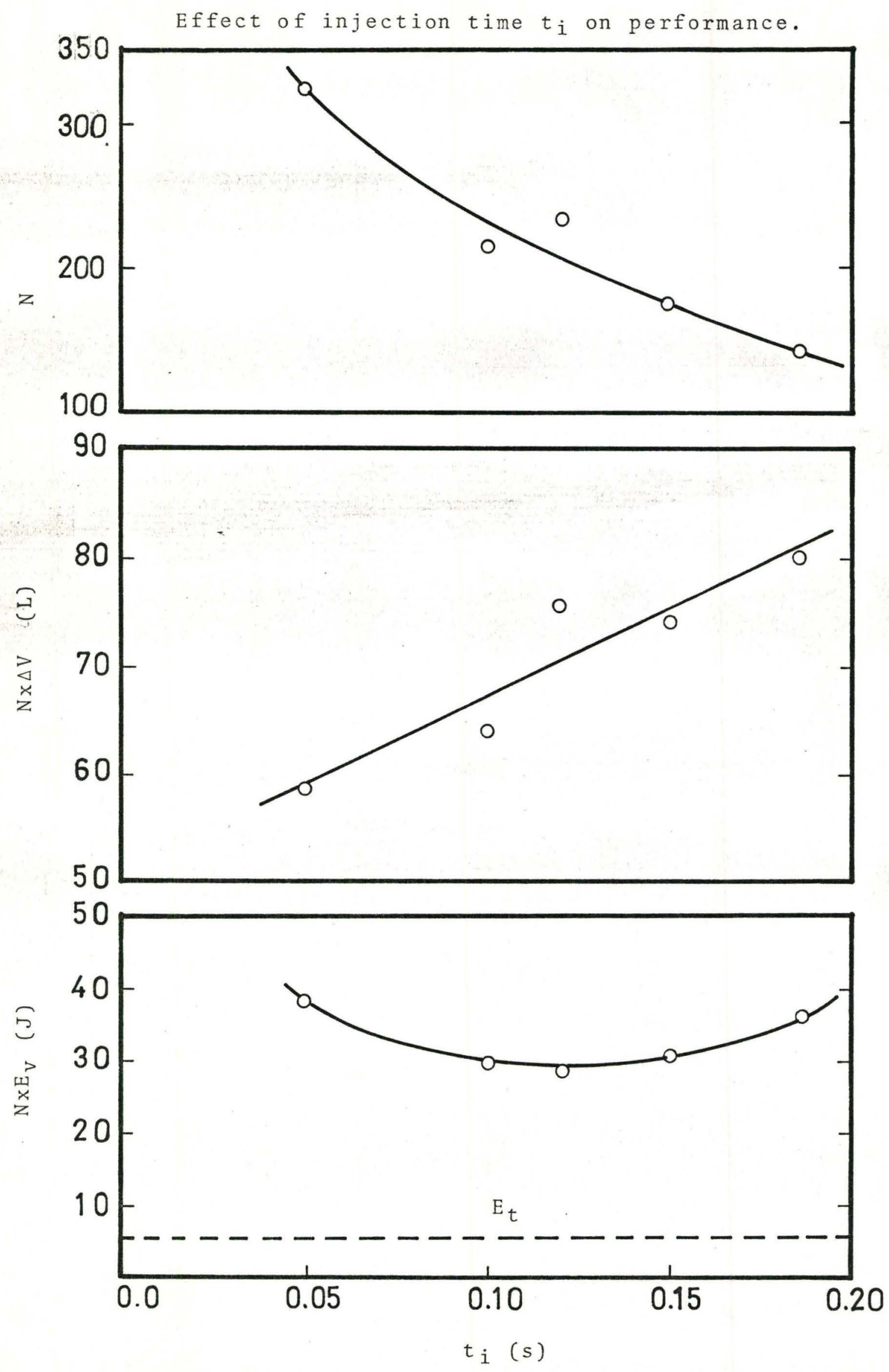
TABLE NO. 5

Effect of injection time $t_{i}$ on performance.

\begin{tabular}{|c|c|c|c|c|c|c|c|c|}
\hline$t_{i}$ & $\begin{array}{l}\Delta \mathrm{V} \\
\mathrm{L}\end{array}$ & $\begin{array}{c}\text { No.of } \\
\text { Vortices } \\
\text { Required } \\
\quad N\end{array}$ & $\begin{array}{c}\mathrm{V}_{\mathrm{a}} \\
\mathrm{N} \times \Delta \mathrm{V} \\
(\mathrm{L})\end{array}$ & $\begin{array}{l}\mathrm{E}_{\mathrm{V}} \\
(\mathrm{J})\end{array}$ & $\begin{array}{l}\mathrm{E}_{\mathrm{a}} \\
\mathrm{NxE}_{\mathrm{V}} \\
(\mathrm{J})\end{array}$ & $\begin{array}{c}\varepsilon \\
\mathrm{E}_{\mathrm{t}} / \mathrm{E}_{\mathrm{a}}\end{array}$ & $\begin{array}{c}\varepsilon_{\mathrm{v}} \\
\mathrm{v}_{\mathrm{t}} / \mathrm{V}_{\mathrm{a}}\end{array}$ & $\frac{\mathrm{u}_{\mathrm{O}} \times \mathrm{t}_{\mathrm{i}}}{\mathrm{d}_{\mathrm{O}}}$ \\
\hline .05 & 0.181 & 325 & 58.82 & 0.118 & 38.35 & 13.71 & 1.25 & 0.9 \\
\hline .10 & 0.305 & 211 & 64.36 & 0.141 & 29.87 & 17.61 & 1.15 & 1.5 \\
\hline .12 & 0.330 & 231 & 76.23 & 0.125 & 28.76 & 18.28 & 0.97 & 1.6 \\
\hline .15 & 0.429 & 174 & 74.65 & 0.175 & 30.46 & 17.27 & 0.99 & 2.1 \\
\hline .18 & 0.561 & 143 & 80.22 & 0.272 & 38.88 & 13.52 & 0.92 & 2.8 \\
\hline
\end{tabular}

$$
\begin{array}{ll}
\mathrm{E}_{\mathrm{t}}=5.26 \mathrm{~J} & \text { Effective 1ighter 1iquid volume } \mathrm{V}_{t}=74 \mathrm{~L} \\
\mathrm{p}=68.9 \mathrm{kPa} & \mathrm{A}_{\mathrm{c}}=0.1076 \mathrm{~m}^{2} \\
\rho_{\mathrm{d}}=1.0412 \mathrm{gm} / \mathrm{cm}^{3} & \\
\mathrm{~V}_{\mathrm{d}}=38 \mathrm{~L} &
\end{array}
$$


reduced. The decrease in efficiency with increasing $t_{i}$ is due to the mechanics of formation of vortex rings. The function $\frac{u_{0} x t_{i}}{a_{0}}$ is a dimensionless number called the dimensionless jet length, see Baird et al (17). Formation of a vortex ring at values of $\frac{u_{0} x t_{i}}{d_{0}}>2$ is not recommended because of turbulent losses (17). In this case, the value of this number begins to exceed two as $t_{i}$ is increased beyond $0.12 \mathrm{~s}$ (at $t_{i}=0.15 \mathrm{~s}$, number $=2.1$ see Table No.5). At values beyond two, not only is the feeding jet slowed by turbulence but some jet turbulence is drawn into the vortex ring itself. It was observed during the course of experiment that the vortex ring at higher values of $t_{i}$ not only slowed down but slowed the recoiling effect. The ring appeared to be just creeping along with a great deal of wake behind it. The volumetric efficiency is better at the smaller formation times because of higher Froude numbers, which means greater recoiling effect. Thus the maximum volumetric efficiency occurs at $0.05 \mathrm{~s}$ ( see Figure No. 5 ).

5.7 EFFECT OF RELATIVE PROPORTIONS OF LIGHT AND DENSE LIQUID:

The effect of $\phi$, the fraction of volume occupied by the dense fluid, on actual energy requirement is shown in Figure 6 and Table 6 . The results suggest that there is not much overall effect of $\phi$, on the actual energy expended to mix the system completely. As regards volumetric efficiency, it can easily be seen from Equation No. 6 that the dotted line 
Figure 6

Effect of volume fraction occupied by dneser fluid on performance
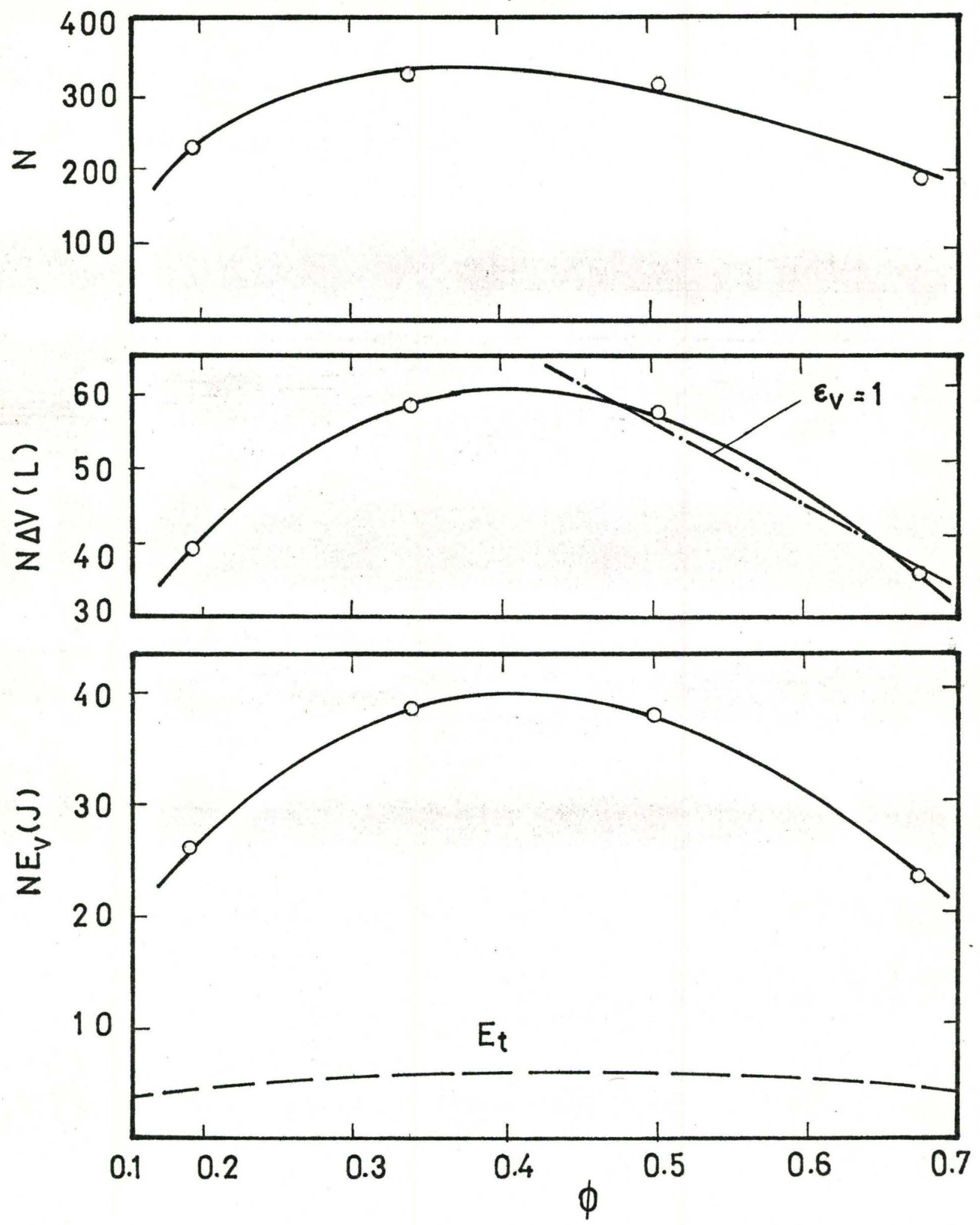
TABLE NO. 6

Effect of dense liquid fraction $\phi$ on performance.

\begin{tabular}{|c|c|c|c|c|c|c|c|c|}
\hline $\begin{array}{l}\mathrm{V}_{\mathrm{d}} \\
(\mathrm{L})\end{array}$ & $\begin{array}{l}\mathrm{V}_{\mathrm{t}} \\
(\mathrm{L})\end{array}$ & $\phi$ & $\begin{array}{l}\text { Average } \\
\text { No.of } \\
\text { Vortices } \\
\text { Required } \\
\text { N }\end{array}$ & $\begin{array}{c}\mathrm{V}_{\mathrm{a}} \\
\mathrm{N} \times \Delta \mathrm{V} \\
(\mathrm{L})\end{array}$ & $\begin{array}{c}\mathrm{E}_{\mathrm{a}} \\
\mathrm{Nx}_{\mathrm{V}}\end{array}$ & $\begin{array}{l}E_{t} \\
(J)\end{array}$ & $\begin{array}{c}\varepsilon_{v} \\
v_{t} / v_{a}\end{array}$ & $\begin{array}{c}\varepsilon \\
E_{t} / E_{a} \\
\%\end{array}$ \\
\hline 20 & 92 & 0.178 & 217 & 39.27 & 25.61 & 3.44 & 2.34 & 13.43 \\
\hline 38 & 74 & 0.339 & 325 & 58.82 & 38.35 & 5.26 & 1.26 & 13.71 \\
\hline 56 & 56 & 0.500 & 317 & 57.38 & 37.41 & 5.87 & 0.98 & 15.69 \\
\hline 76 & 36 & 0.678 & 195 & 35.29 & 23.01 & 5.12 & 1.02 & 22.25 \\
\hline
\end{tabular}

$\begin{aligned} \rho & =68.9 \mathrm{kPa} & \rho_{\mathrm{d}} & =1.0412 \mathrm{gm} / \mathrm{cm}^{3} \\ \Delta \mathrm{V} & =0.181 \mathrm{~L} & \mathrm{t}_{\mathrm{i}} & =.05 \mathrm{~s}\end{aligned} \mathrm{~A}_{\mathrm{c}}=0.1076 \mathrm{~m}^{2}$


to the right of the middle section of Fig. 6 represents $\varepsilon_{\mathrm{V}}=1$. In this case, the agreement with the data indicates that mixing occurs simply by displacement of the light liquid into the dense layer. At low values of $\phi$, the volumetric efficiency exceeds unity because the recoil effect becomes quite significant in the relatively small layer of dense liquid. Energy efficiencies however remained rather low because the vortex rings used in this study were capable of penetrating longer distances than the maximum height of the denser fluid, in other words, they still had kinetic energy left at the bottom of the tank to be converted into mixing energy. In fact, if the rectangular tank was of 2 to $3 \mathrm{~m}$ height, one would have observed an appreciable improvement in the energy efficiency relative to that indicated in Figure 6, because a great deal more of kinetic energy could have been converted into mixing energy before the impact at the bottom of the tank. In general one can say that by having the vortex rings with slower velocities capable of just reaching the tanks bottom, the efficiency of mixing may be improved, since this will ensure maximum transformation of kinetic energy into mixing energy i.e. potential energy• 
CHAPTER 6

\section{LARGE VORTEX RINGS}

6.1 INTRODUCTION: The ring vortices produced at a $6.35 \mathrm{~cm}$ orifice and discussed in chapter 5 served the purpose of studying the mixing parameters on a laboratory scale, but they carry very small volumes of liquids and therefore, cannot be used for most of the applications mentioned earlier. Consequently, a bigger vortex generator with an orifice of $25.4 \mathrm{~cm}$ was designed to displace larger volumes of liquids. Mixing tests with a thermocline have been conducted in Hamilton Harbour with this sized orifice vortex generator. The results of these experiments are discussed by Baird (19). The following chapters describe measurements of the range, velocity and momentum of large vortex rings generated at a $25.4 \mathrm{~cm}$ orifice in a large water tank at the Canada Centre of Inland Waters (CCIW). This is hoped to provide useful hydrodynamic data as a background to further work on large scale mixing.

6.2 EXPERIMENTAL APPARATUS:

6.2.1 TEST TANK: The dimensions of the CCIW water tank were approximately $120 \times 4 \times 3 \mathrm{~m}$. Mounted on the side walls of this tank was an electric carriage capable of travelling on 
SCHEMATIC EXPERIMENTAL ARRANGEMENT FOR GENERATION OF LARGE RING VORTICES, AND MEASUREMENT OF RING VELOCITY AND MOMENTUM.

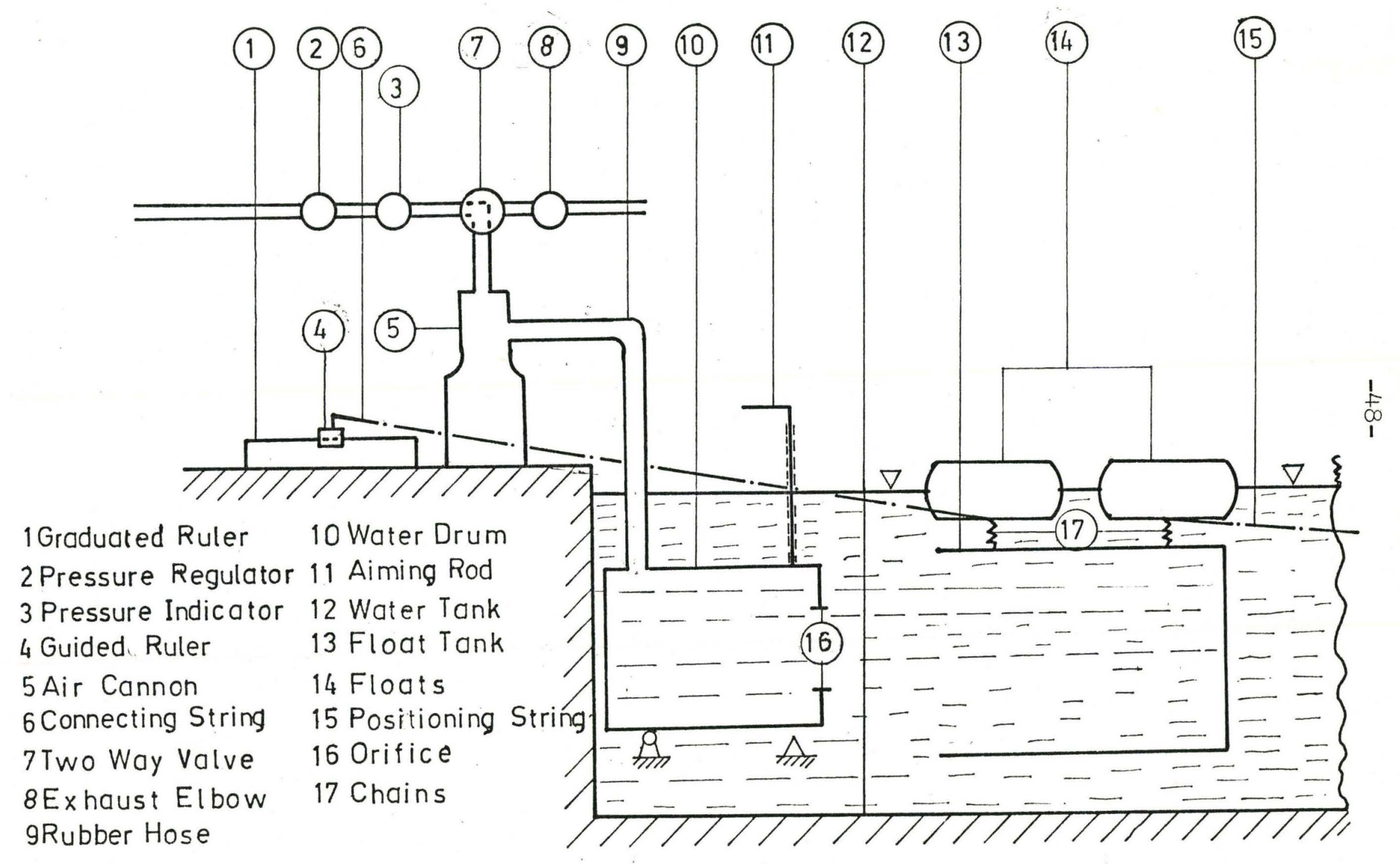


rails along the tank at speeds sufficient to follow the movement of the vortex rings. The movement of the carriage did not create any movement in the tank water. There were three under water observation windows installed along the first $10 \mathrm{~m}$ of the tank. They facilitated the observation of initial movement of the rings. The tank was graduated lengthwise in $1 \mathrm{~m}$ intervals.

6.2.2 GENERATION OF LARGE VORTEX RINGS: A principle sketch of a large vortex generator is shown in Figure 7. It consisted of a standard 45 gallons steel drum into the lid of which a $25.4 \mathrm{~cm}$ orifice was cut. The drum was pivoted at the closed end as shown in Figure 7, and at the other end an aiming control rod was mounted. The control rod facilitated the movement ( upwards or downwards) of the drum so that the drum could be aimed slightly above or below the horizontal. Compressed air was introduced from the cannon into the drum through a $2 "$ flexible rubber hose. At the top of the cannon was mounted a three way valve. By shifting the valve in the left position, the cannon was pressurised to a desired pressure from an air line and a pressure regulator. By moving the valve in the right position, the air was very rapidly released to the drum, thereby displacing the water from the drum in the form of a ring vortex. The cannon is manufactured by Martin Engineering Company of U.S.A. ( type No. BB2-8-12). Figure 8, which is reproduced from the manufacturer's catalogue, illustrates the operation of the air cannon or "Big Blaster" 


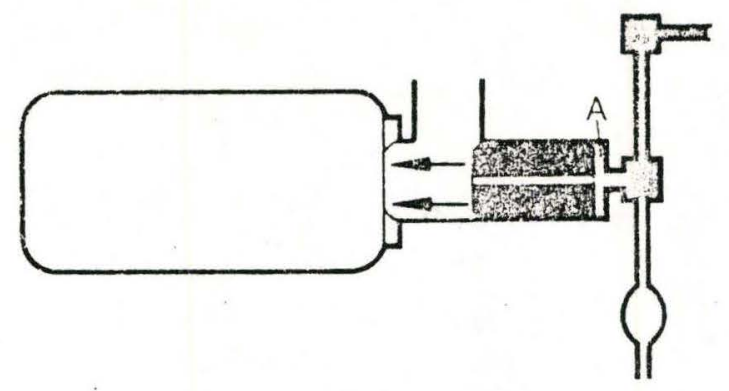

1.

To charge the BIG

BLASTER* Air Cannon

chamber: Open three-way valve so air from

compressor activates quick exhaust valve and fills Chamber A.

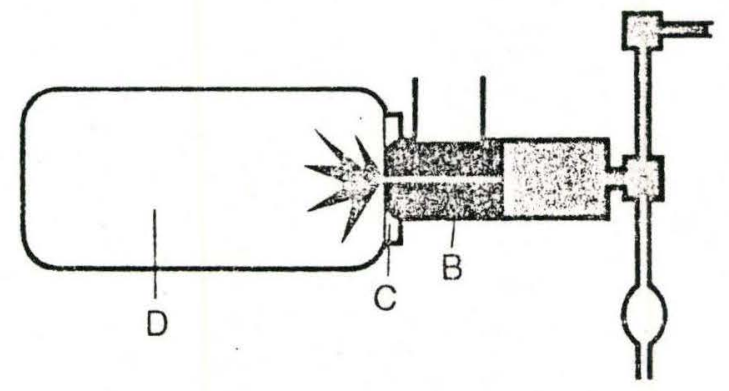

?.

Air in Chamber $A$ forces Piston $B$ onto Seat $C$ and fills Chamber $D$.

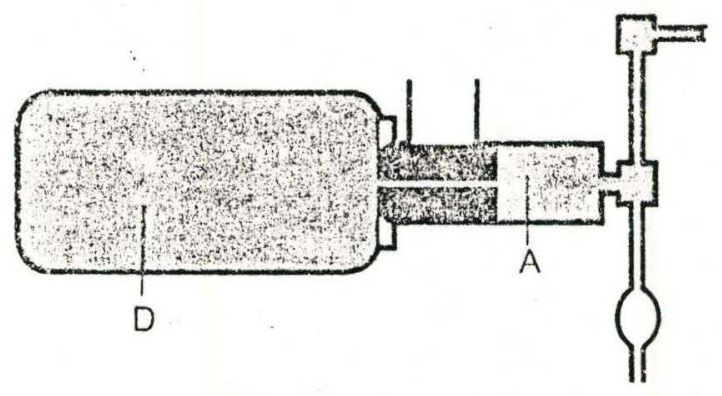

\section{3.}

Air through Chamber A enters Chamber D through port in piston.
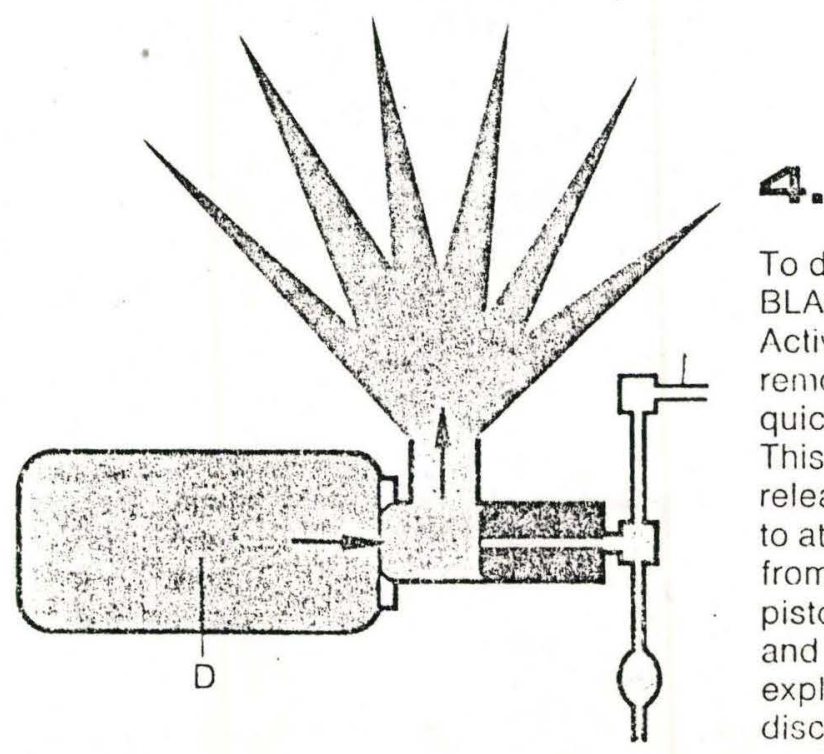

To discharge the BIG BLASTER $^{*}$ Air Cannon: Activate three-way valve to remove line pressure from quick exhaust valve. This fast acting valve releases air in Chamber $A$ to atmosphere. Pressure from Chamber D forces piston back into air space $A$ and air in Space D explodes out through discharge tube. 
as it is generally called.

6.2.3 FLOAT TANK AND RIDER FOR MONENTUM MEASUREMENTS: The vortex ring momentum was measured by allowing the ring to enter a large, floating plastic tank ( see Figure ?). The masses of the tank, floats, contained water and the virtual mass assumed to be equivalent to the mass of water contained in a hemisphere of radius of the plastic floating tank are known (effective mass $1514 \mathrm{~kg}$ ). Vortex momentum was taken to be the product of the total effective mass and the initial velocity of the float tank just after impact of the vortex ring.

The float tank was a polythene cylinder closed at one end. Its internal diameter and length were 1.067 and $2.286 \mathrm{~m}$ respectively. Attached along its circumference were two steel straps $1 \mathrm{~m}$ apart. Two metal floats weighing each $9.52 \mathrm{~kg}$ were connected to the steel straps by $50 \mathrm{~cm}$ lengths of metal chain. The chains and floats were chosen in such a way that the float tank could be submerged in water to a depth such that the centre of the float tank circular cross section and the centre of the orifice of the vortex generator drum lay in horizontal straight line parallel to the level of water of the test tank. A length of light string was tied to the rear top end of this float tank. The other end of this string allowed the operator to align the 
tank, so that vortex rings entered the open end of the float tank at the centrepoint. Another piece of light string was tied on the top of front end of the float tank. The other end of this string was connected to a nail attached to the movable rider. The rider was made out of wood and was placed on the top of a measuring rule. To minimise the friction between the measuring rule and the rider, the contact area was reduced as much as possible by cutting away a portion of the rider from its bottom. The movement of the float tank after vortex impact could be followed as the rider was dragged along the rule by this second string.

\subsection{PROCEDURES:}

6.3.1 RANGE AND VELOCITY: The calculation of the initial velocity of a vortex ring was discussed in chapter 3. It involved the prior knowledge of the formation time $t_{i}$, the orifice diameter and the amount of air injected. Unfortunately, the formation time in the case of larger vortex rings could not be measured. The velocity was determined experimentally, at various points well away from the orifice.

Consider the arrangement shown in Figure 7 without the float tank and rider mechanism. The vortex ring issues from the orifice and travels horizontally along the length of the test tank, which was graduated in $1 \mathrm{~m}$ 
intervals. The movable carriage followed the motion of the ring which was visible as a few small entrained air bubbles. The distance and time readings were recorded. The vortex rings were formed at four different pressures 275.8, 344.7, 413.7 , and $482.6 \mathrm{kPa}$. The distance versus time data are given in Tables 7 and 7 a for the pressures mentioned above.

6.3.2 NATURE OF DRAG FORCES ACTING ON A LARGE VORTEX RING:

Laminar drag model

Consider a vortex ring moving with a velocity $u_{v}$ and mass $\mathrm{m}_{\mathrm{v}}$. In a laminar flow the drag force is considered proportional to the velocity of the ring. Thus the differential equation describing the motion of the ring is as follows :

$$
\frac{d u_{v}}{d t} \alpha-u_{v}
$$

and the solution is ( given $X=0$ at $t=0$ ):

$$
X=A\left(1-e^{-B t}\right)
$$

Where $\mathrm{A}$ and $\mathrm{B}$ are parameters, and $\mathrm{X}$ is the distance travelled in time $t$. 
Turbulent model

If the flow is considered turbulent, the drag force is proportional to $u_{v}^{2}$ and the differential equation is as follows :

$$
\frac{d u_{v}}{d t} \alpha-\left(u_{v}^{2}\right)
$$

and the solution is ( given $X=0$ at $t=0$ ):

$$
X=P \ln (1+Q t)
$$

where $P$ and $Q$ are parameters.

These two simple alternative models will be compared with the velocity data in section 8.2

6.3.3 MOMENTUM OF A LARGE VORTEX RING: The momentum of a body is defined as the product of the mass and velocity. To measure the translational momentum of the large vortex ring, it was necessary that its mass and velocity were known. Baird et al (17) suggested a methodology to estimate the initial momentum of a vortex ring by estimating the forming jet mass and velocity. The relevant equations were given in section 3.3. Unfortunately, the formation time $t_{i}$ of the vortex ring was unknown in the case of large vortex rings produced by the vortex generator described in section 6.2 .2 because 
the release of air was so rapid that it could not be measured. Hence the momentum of a large vortex ring was measured by the following procedure.

Consider a large vortex ring with a mass $\mathrm{m}_{\mathrm{v}}$, travelling with a velocity $\mathrm{u}_{\mathrm{v}}$ and this vortex strikes another object which was originally stationary. Upon impact the object started to move with a certain velocity $u_{F}$. Also assume that the vortex had imparted its translational momentum completely upon impact to the other body. Then the momentum of a vortex ring is given by:

$$
I_{v}=m_{v} \times u_{v}=m_{F} \times u_{F}
$$

where $m_{F}$ and $u_{F}$ refer to the effective mass and velocity of the struck body ( float tank). Both these quantities can be measured.

6.3.4 EXPERIMENTAL DETERMINATION OF MOMENTUM OF A LARGE VORTEX RING : A principle sketch describing the apparatus for the determination of vortex momentum is shown in Figure 7 . The vortex generator was lowered into water and was held fixed during the operation. The float tank was submerged into the test tank and its submergence depth was controlled by adjusting the length of the two chains connecting the two floats to the float tank. The submergence depth was so adjusted that the centre of the orifice on the firing drum and the 
centre of the cross section of the float tank lay in a horizontal straight line. The piece of string whose one end was tied to the rear end of the float tank was used to align the float tank horizontally so that the whole vortex ring entered the float tank in the middle. The positioning of the float tank was necessary because if the vortex ring entered the float tank towards the side, the entire momentum of the ring would not be imparted axially to the float tank and consequently, the float tank might twist rather than travel in a straight line. After adjusting the position of the float tank the string was left loose. The other piece of string whose one end was connected to the front end of the float tank and the other connected to the rider was stretched gently and placed over the graduated measuring rod. As the vortex ring hit the float tank, it began to move and thus drew the rider along with the same velocity. The distances moved by the rider and times taken were recorded. The slope of the curve distance versus time gave the required velocity with which the float tank moved upon impact with the ring.

\section{The float tank's displacement readings} were taken at $275.8,344.7$ and $413.6 \mathrm{kPa}$. Also for each pressure the horizontal distance between the orifice and the front end of the float tank was varied at 5, 10, and $15 \mathrm{~m}$. The data, distance versus time for these experiments, are given in Table No. 10. The summary of averaged displacements, 


\section{$-57-$}

versus time is given in Table No. 10a. The plots of averaged distance versus time data are shown in Figures 17, 18, 18a, and 19. The curves were drawn by visual inspection only. From the initial linear portion of these curves, the respective slopes were obtained, which gave the velocities of the float tank at different pressures and at various distances from the orifice. 
CHAPTER ?

RESULTS

7.1 VELOCITY DETERMINATION OF A VORTEX RING AT THE ORIFICE:

The distance versus time measurements at operating pressures $275.8,344.7,413.7$ and $482.6 \mathrm{kPa}$ are presented in Tables 7 and 7 a. This data were fitted to laminar and turbulent models as described in chapter 6.3 .2 and the parameters $A$, $B, P$, and $Q$ were accordingly determined. The regression was non-linear. Based on the estimated values of the parameters, the values of vortex velocities at $X=0$ (at orifice) were calculated and are presented in Table 8. Table No. 9 presents the statistical data and the analysis of the variances. The measured and regressed values of distance, versus time are plotted in Figures 9-16.

7.2 VORTEX RING MOMENTUM ESTIMATION:

7.2.1 FLOAT TANK'S VEIOCITY ESTIMATION : It was described earlier that the incoming vortex ring entered the float tank and thereby caused it to move with a velocity $u_{F}$. This velocity was determined from the initial slope of the curves plotted in Figures 17, 18, 18a and 19 for three operating pressures $275.8,344.7$, and $413.7 \mathrm{kPa}$ and at three positions of the float tank at 5, 10, and $15 \mathrm{~m}$ from the vortex generator respectively. The curves were drawn by eyeballing only and the initial portion of these curves appeared straight. 
Table No.?

Distance vs time measurements for large vortex velocity determination.

Operating pressure: $\underline{275.8 \mathrm{kPa}}$

\begin{tabular}{|l|c|c|c|c|c|c|c|}
\hline $\begin{array}{l}\text { Time } \\
(\mathrm{s})\end{array}$ & $\begin{array}{c}\text { Dist. } \\
(\mathrm{m})\end{array}$ & $\begin{array}{c}\text { Time } \\
(\mathrm{s})\end{array}$ & $\begin{array}{c}\text { Dist. } \\
(\mathrm{m})\end{array}$ & $\begin{array}{c}\text { Time } \\
(\mathrm{s})\end{array}$ & $\begin{array}{c}\text { Dist. } \\
(\mathrm{m})\end{array}$ & $\begin{array}{c}\text { Time } \\
(\mathrm{s})\end{array}$ & $\begin{array}{c}\text { Dist. } \\
(\mathrm{m})\end{array}$ \\
\hline 5 & 10 & 15 & 13 & 18 & 20 & 23 & 21 \\
5 & 10 & 17 & 18 & 21 & 20 & 33 & 25 \\
5 & 10 & 20 & 18 & 19 & 20 & 35 & 28 \\
6 & 10 & 19 & 19 & 27 & 20.5 & 70 & 33 \\
\hline Operating pressure : & 344.75 & $\mathrm{kPa}$ & & & \\
4 & 10 & 14.5 & 20 & 23 & 25 & 47.5 & 33 \\
5 & 10 & 14 & 20 & 25 & 26 & 51 & 34 \\
7 & 13 & 15 & 20 & 27 & 26 & 55 & 35 \\
7 & 13 & 16 & 20 & 30 & 27.5 & 59 & 36 \\
9 & 15 & 17 & 22 & 32 & 28 & 63 & 37 \\
10 & 16 & 18 & 22 & 35 & 29 & 67 & 38 \\
10 & 16 & 18 & 22 & 36 & 30 & 72 & 39 \\
12 & 18 & 20 & 24 & 38 & 30 & 77 & 40 \\
16 & 18 & 21 & 24 & 41 & 31 & 86 & 42 \\
\hline & 18 & 23 & 24 & 44 & 32 & 110 & 46.7 \\
\hline
\end{tabular}


Table No. $7 a$

Distance vs time measurements for large vortex velocity determination:

Operating pressure: $413.7 \mathrm{kPa}$

Time Dist. Time Dist. Time Dist. Time Dist.

$\begin{array}{llllllll}(\mathrm{s}) & (\mathrm{m}) & (\mathrm{s}) & (\mathrm{m}) & (\mathrm{s}) & (\mathrm{m}) & (\mathrm{s}) & (\mathrm{m}) \\ 4 & 10 & 10 & 18 & 15 & 22 & 35 & 28 \\ 5 & 12 & 12 & 18 & 20 & 24 & 25 & 28 \\ 6 & 13 & 13.5 & 20 & 23 & 24 & 39 & 29 \\ 7 & 14 & 15 & 20 & 17.5 & 24 & 43 & 30 \\ 8 & 15 & 12 & 20 & 18 & 24 & 29.5 & 30 \\ 8 & 15 & 11.5 & 20 & 26 & 25 & 47.5 & 31 \\ 9.5 & 16 & 17.5 & 22 & 29 & 26 & 32.5 & 31 \\ 10 & 17 & 19 & 22 & 21 & 26 & 52 & 31.5 \\ 9.5 & 17 & 14.5 & 22 & 21.5 & 26 & & \end{array}$

Operating pressure: $482.65 \mathrm{kPa}$

$\begin{array}{llllllll}3.5 & 10 & 8 & 17 & 16 & 23 & 23 & 30 \\ 4 & 10 & 9 & 17 & 15 & 24 & 29 & 30 \\ 3.5 & 10 & 11 & 19 & 17.5 & 25 & 26.5 & 32 \\ 5.5 & 11 & 12 & 19 & 16.5 & 26 & 34 & 32 \\ 5 & 13 & 11 & 20 & 18.5 & 26 & 38 & 33 \\ 9 & 13 & 11.5 & 20 & 23 & 27 & 30 & 34 \\ 6 & 14 & 13 & 21 & 22.5 & 27 & 41 & 34 \\ 6 & 14 & 12.5 & 22 & 19.5 & 28 & 44 & 35 \\ 8 & 15 & 15 & 23 & 27 & 29 & 34 & 35.5\end{array}$


Table No. 8

Determination of large vortex ring velocity at $\mathrm{X}=0$, by non-linear regression of measured data.

Laminar model

Function fitted: $X=A\left(1-e^{-B t}\right)$

$$
\frac{d X}{d t}=A B e^{-B t}
$$

\begin{tabular}{|l|c|c|c|}
\hline $\begin{array}{c}\text { Operating } \\
\text { pressure } \\
\mathrm{kPa}\end{array}$ & $\mathrm{A}$ & $\mathrm{B}$ & $\left(\frac{\mathrm{dX}}{\mathrm{dt}}\right)_{\mathrm{t}=0}=\mathrm{u}_{\mathrm{v} / \mathrm{s}}$ \\
\hline 275.8 & 32.83 & .0465 & 1.527 \\
\hline 344.7 & 43.91 & .0357 & 1.569 \\
\hline 413.7 & 30.75 & .0820 & 2.522 \\
\hline 482.6 & 36.28 & .0700 & 2.540 \\
\hline
\end{tabular}

Turbulent Model

Function fitted:

$$
\begin{aligned}
& X=P \ln (1+Q t) \\
& \frac{d X}{d t}=P Q /(1+Q t)
\end{aligned}
$$

\begin{tabular}{|l|c|c|c|}
\hline $\begin{array}{c}\text { Operating } \\
\text { pressure } \\
\mathrm{kPa}\end{array}$ & $\mathrm{P}$ & $\mathrm{Q}$ & $\begin{array}{c}\left(\frac{\mathrm{dX}}{\mathrm{dt}}\right)_{\mathrm{t}=0}=\mathrm{u}_{\mathrm{v}} \\
\mathrm{m} / \mathrm{s}\end{array}$ \\
\hline 275.8 & 11.64 & .2220 & 2.586 \\
\hline 344.7 & 14.71 & .1885 & 2.773 \\
\hline 413.7 & 10.29 & .4522 & 4.653 \\
\hline 482.6 & 14.28 & .2657 & 3.794 \\
\hline
\end{tabular}


TABLE NO. 9

Variance analysis.
Mode 1
\# (1)
$x=A\left(1-e^{-B T}\right)$
Laminar drag
(2)
$x=P \ln (1+Q t)$
Turbulent drag

\begin{tabular}{|c|c|c|c|c|c|c|c|c|c|c|c|}
\hline $\begin{array}{c}\text { Mode } 1 \\
\text { No. }\end{array}$ & $\begin{array}{c}\text { Operating } \\
\text { Pressure } \\
\text { kPa }\end{array}$ & and & $\begin{array}{l}\text { Estimated.P } \\
\text { approximate } \\
\text { Interv } \\
\text { B }\end{array}$ & $\begin{array}{l}\text { ame ters } \\
5 \% \text { confidenc } \\
\text { P }\end{array}$ & Q & SSR & $\begin{array}{l}\text { Degrees } \\
\text { of freedom }\end{array}$ & $\hat{\sigma}^{2} \operatorname{Residua} 1$ & $\begin{array}{l}\hat{\sigma}_{1}^{2} / \hat{\sigma}^{2} 2 \\
\text { or } \\
\hat{o}^{2}{ }_{2} / \hat{\theta}_{1} 2\end{array}$ & $\begin{array}{l}F\left(\mu_{2} . \mu_{2}\right) \\
0.95\end{array}$ & $\begin{array}{l}\text { Reject } \\
\quad \text { or } \\
\text { Accept } \\
\text { Hypothesis }\end{array}$ \\
\hline $\begin{array}{l}1 \\
2\end{array}$ & 275.8 & $32.83 \pm 1.50$ & $.046 \pm .015$ & $11.64 \pm 2.795$ & $.22 \pm .116$ & $\begin{array}{l}67.40 \\
39.16\end{array}$ & $\begin{array}{l}14 \\
14\end{array}$ & $\begin{array}{l}4.81 \\
2.80\end{array}$ & 1.71 & 2.46 & $\operatorname{Reject}$ \\
\hline $\begin{array}{l}1 \\
2\end{array}$ & 344.7 & $43.92 \pm 2.85$ & $.0357 \pm .009$ & $14.71 \pm 0.660$ & $.1885 \pm .020$ & $\begin{array}{l}34.11 \\
31.95\end{array}$ & $\begin{array}{r}39 \\
39\end{array}$ & $\begin{array}{r}8.74 \\
.82\end{array}$ & 10.67 & 1.69 & Accept \\
\hline $\begin{array}{l}1 \\
2\end{array}$ & 413.7 & $30.75 \pm 1.17$ & $.08204 \pm .023$ & $10.29 \pm 1.127$ & $.4522 \pm .127$ & $\begin{array}{l}50.96 \\
51.70\end{array}$ & $\begin{array}{l}33 \\
33\end{array}$ & $\begin{array}{l}1.54 \\
1.57\end{array}$ & 1.01 & 1.84 & $\operatorname{Reject}$ \\
\hline 1 & 482.6 & $36.28 \pm 1.67$ & $.07005 \pm .007$ & $14.28 \pm 1.590$ & $.2657 \pm .065$ & $\begin{array}{l}78.17 \\
74.93\end{array}$ & $\begin{array}{l}35 \\
35\end{array}$ & $\begin{array}{l}2.23 \\
2.14\end{array}$ & 1.04 & 1.84 & Reject \\
\hline
\end{tabular}

Hypothesis: $\sigma_{1}{ }^{2}>\sigma_{2}{ }^{2}$ or $\sigma_{2}{ }^{2}>\sigma_{1}{ }^{2}$

Test: $\quad \frac{\hat{\partial}_{1}{ }^{2}}{\hat{\partial}_{2}}>F_{0.95}\left(\mu_{1}, \mu_{2}\right)$ 
Figure 9

Comparison of measured values of distance vs time with fitted values from

laminar drag model for large vortex rings.

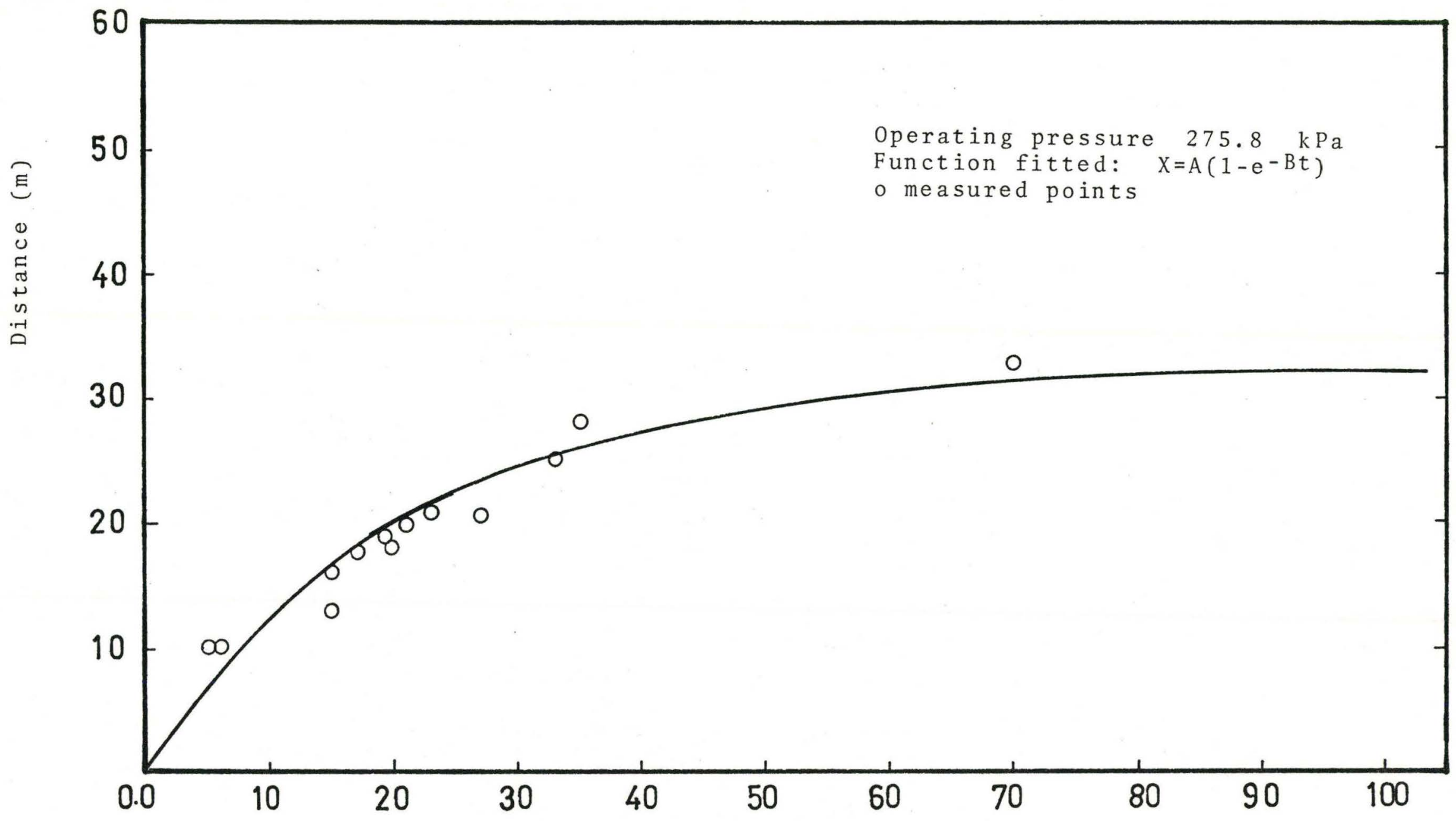

Time (s) 
Figure 10

Comparison of measured values of distance vs time with fitted values from turbulent drag model for large vortex rings.

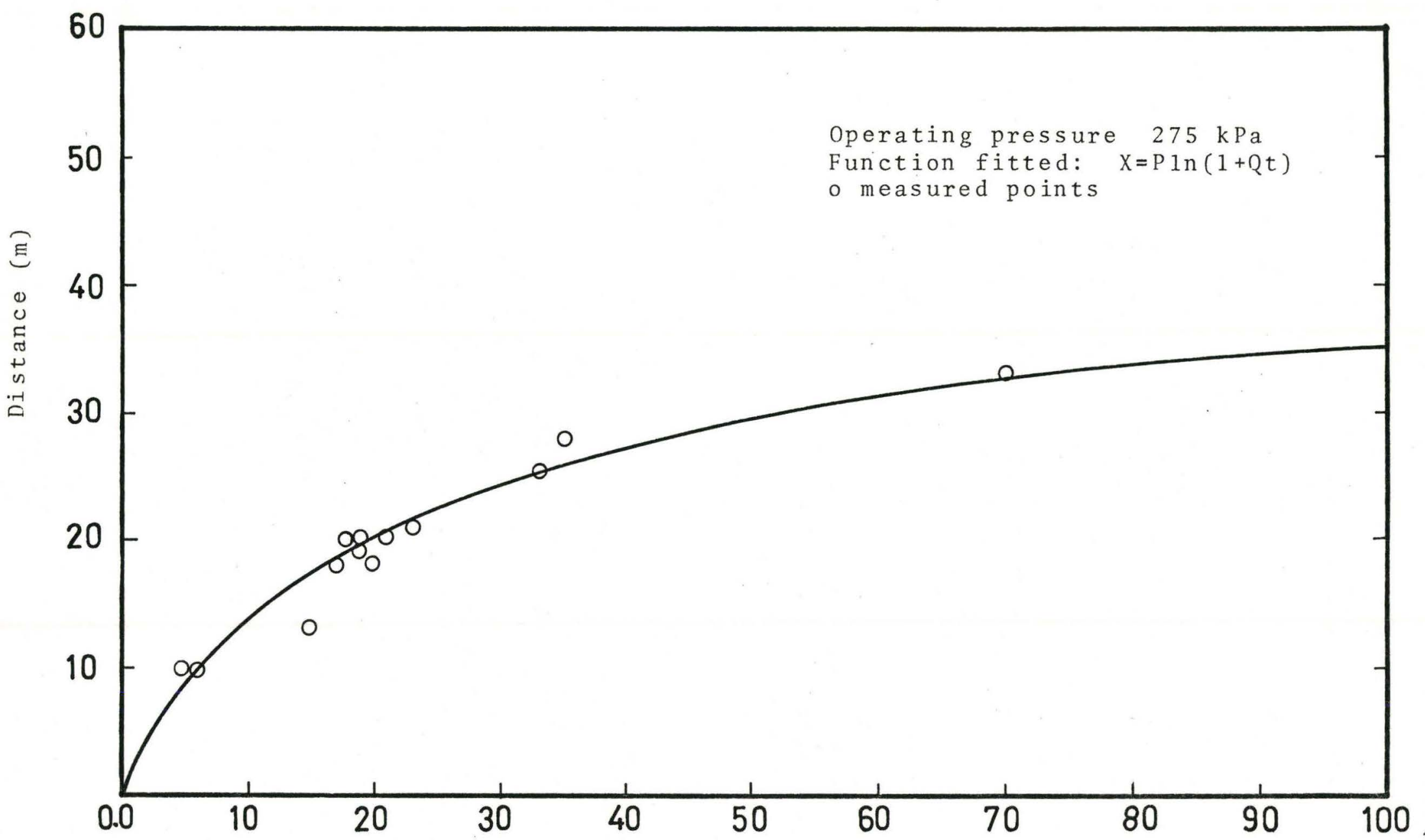

Time (s) 
Figure 11

Comparison of measured values of distance vs time with fitted values from laminar drag model for large vortex rings.

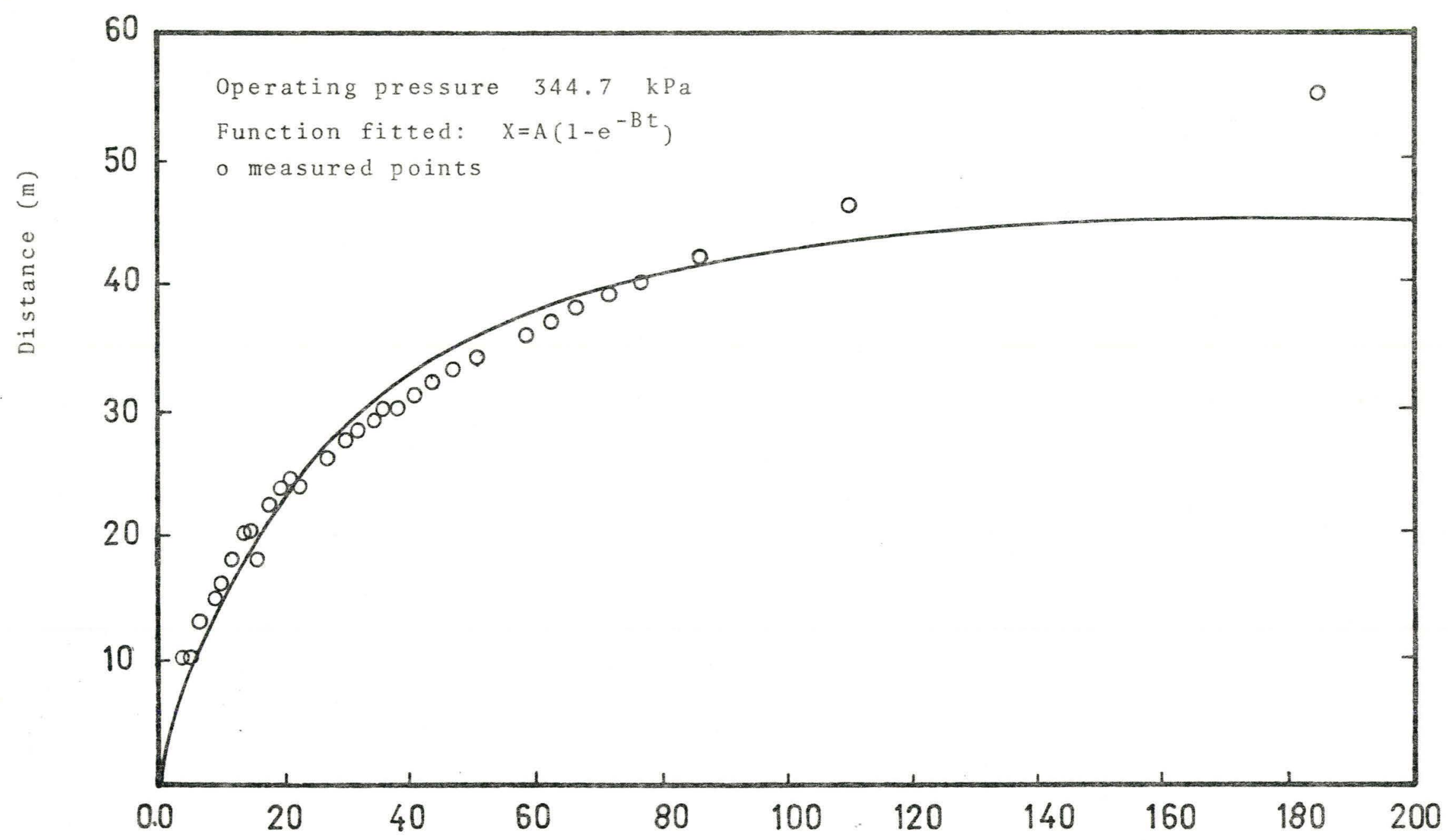

Time (s) 
Figure 12

Comparison of measured values of distance vs time with fitted values from turbulent drag model for large vortex rings.

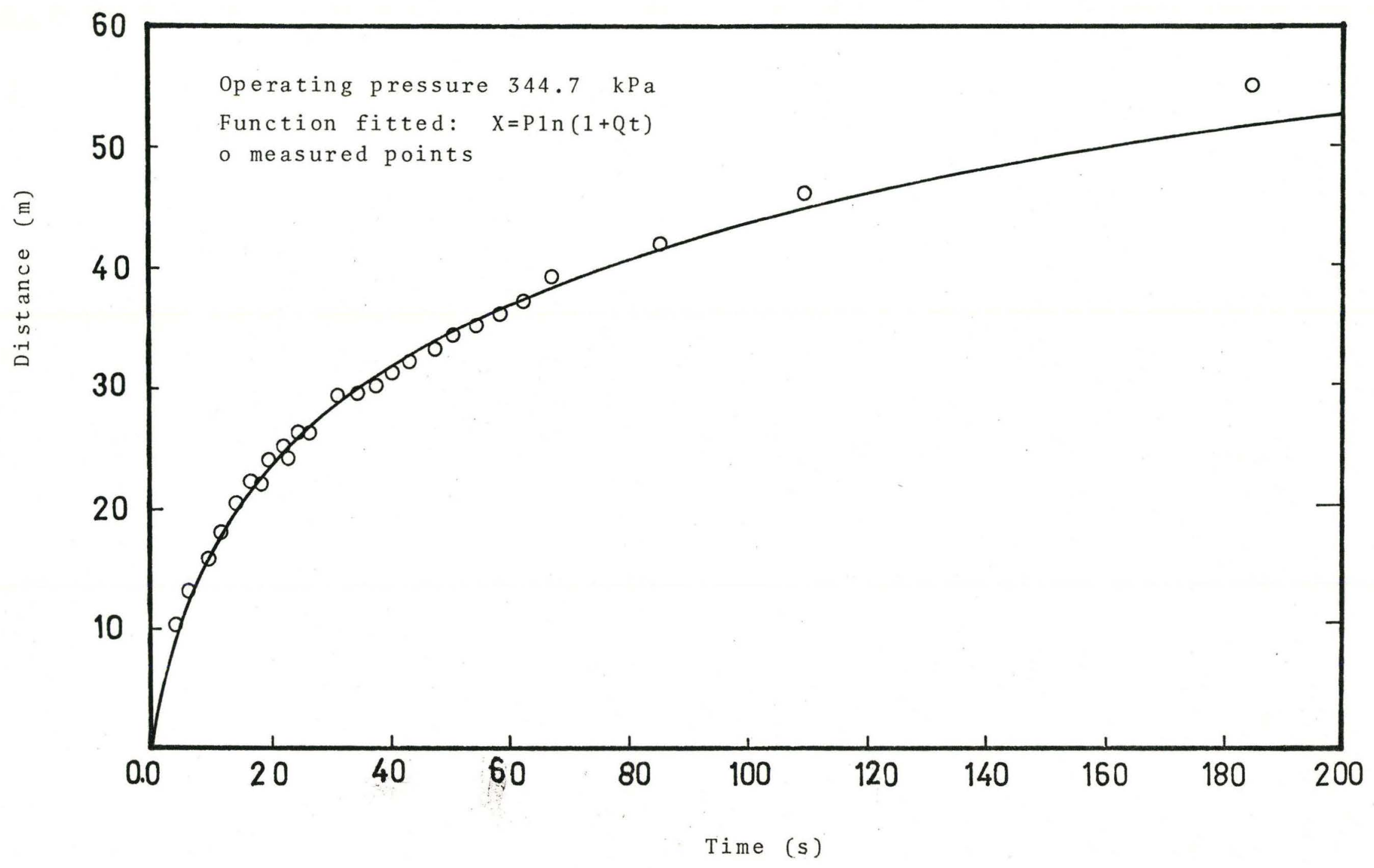


Figure 14

Comparison of measured values of distance vs time with fitted values from

turbulent drag model for large vortex rings.

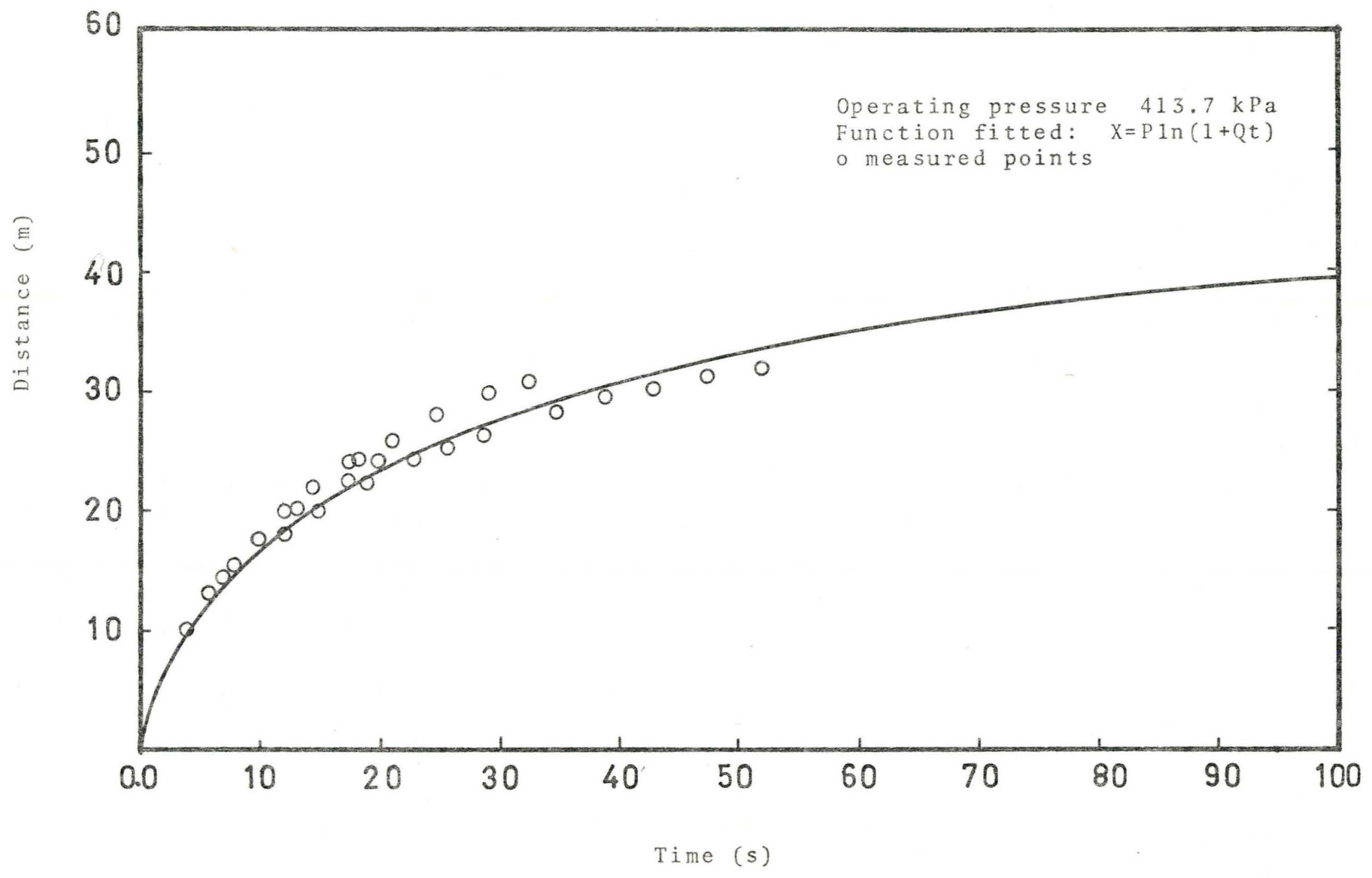


Figure 15 Comparison of measured values of distance vs time with fitted values from
laminar drag model for large vortex rings.

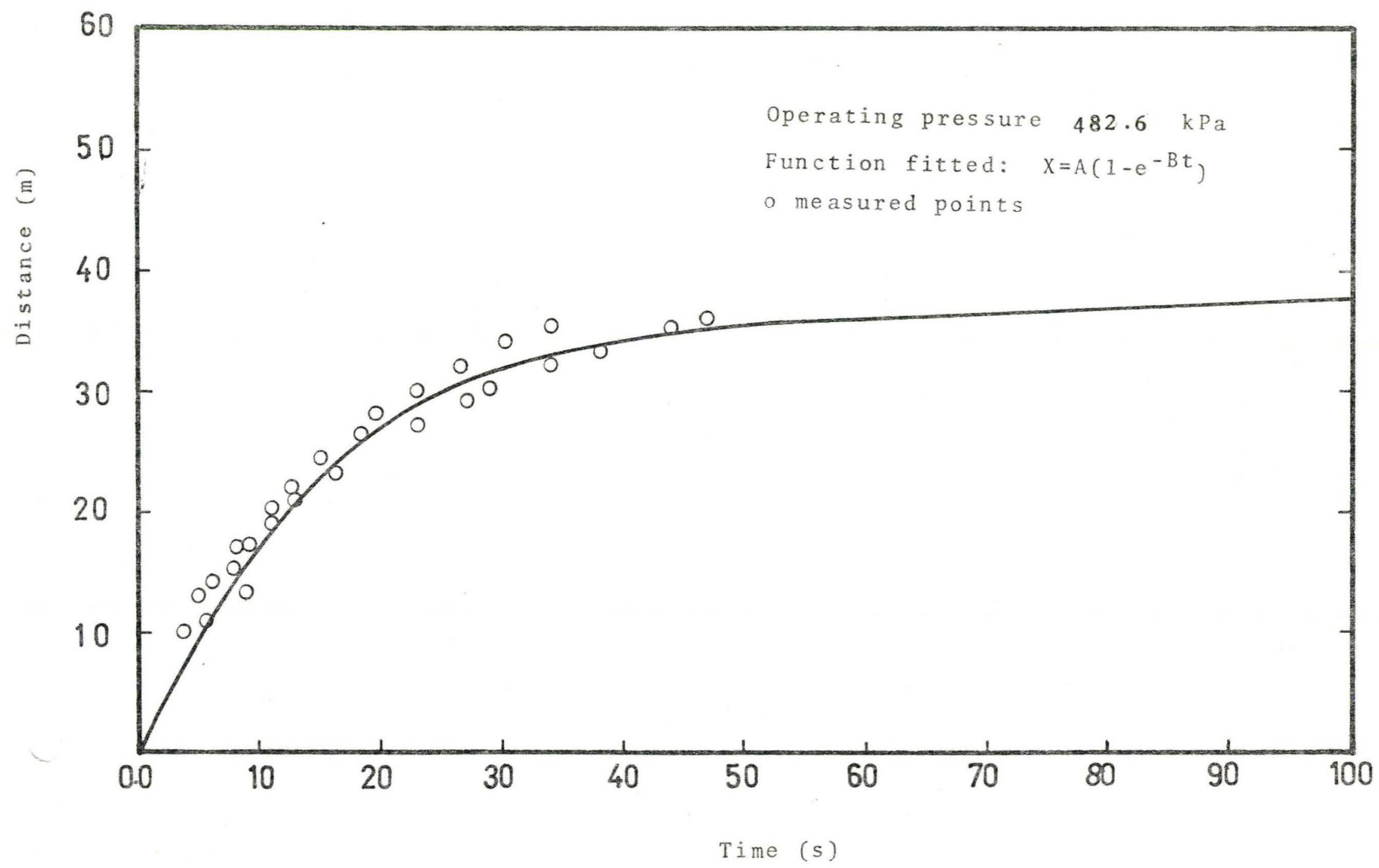


Figure 16

Comparison of measured values of distance vs time with fitted values from

turbulent drag model for large vortex rings.

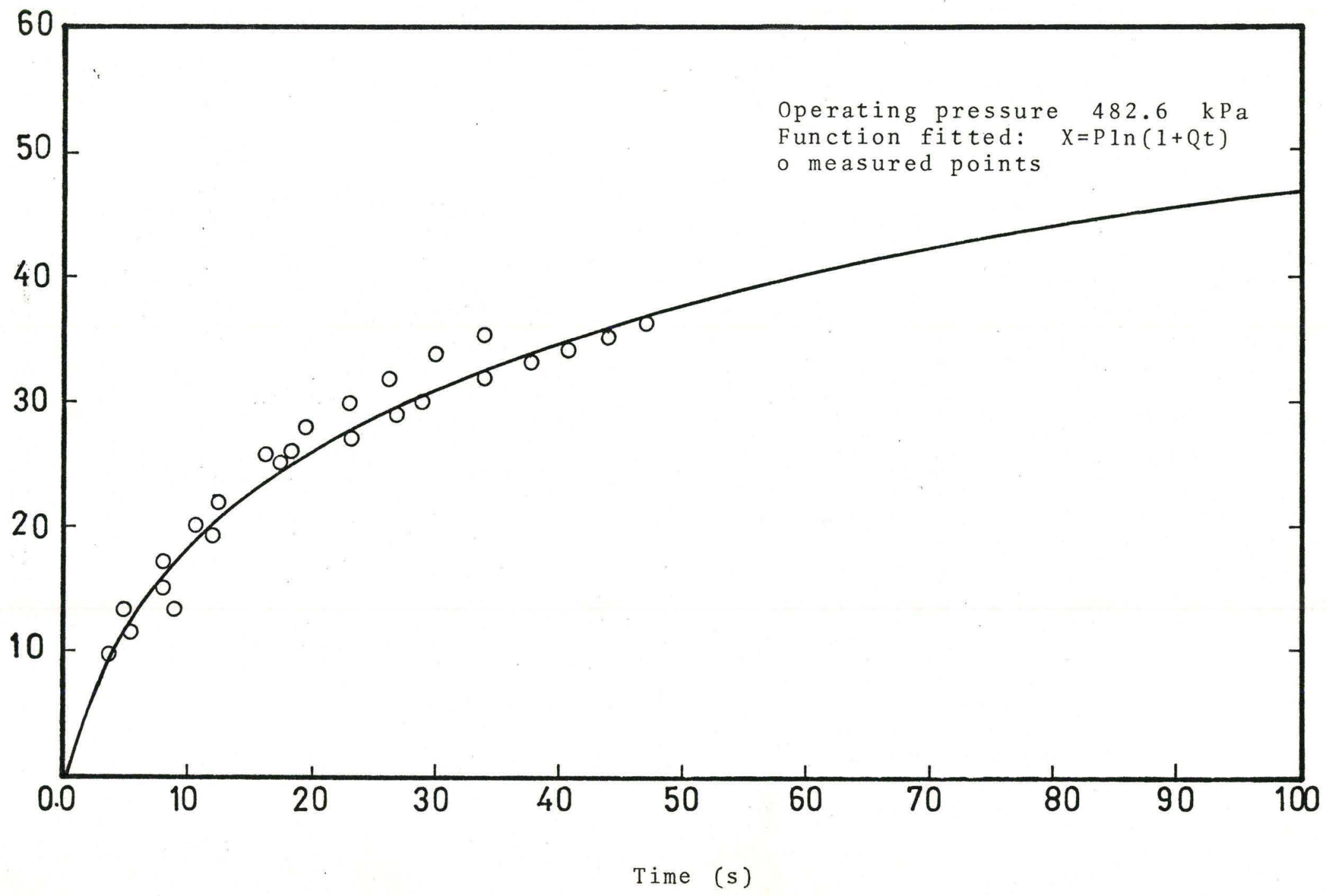


Table No. 10

Momentum meaurements at CCIW with float tank (eff. mass $1514 \mathrm{~kg}$ ) Displacements of float tank given in $\mathrm{cm}$.

Operating pressure: $275.8 \mathrm{kPa}$

\begin{tabular}{|c|ccc|c|cccc|}
\hline $\begin{array}{l}\text { Time from } \\
\text { firing(s) }\end{array}$ & \multicolumn{2}{|c|}{$\begin{array}{c}\text { Float positions } \\
\text { at }\end{array}$} & $\begin{array}{c}\text { Positions } \\
\text { @ } 10 \mathrm{~m} \text { range }\end{array}$ & \multicolumn{4}{|c|}{$\begin{array}{c}\text { Positions } \\
\text { @ 15m }\end{array}$} \\
\hline 0 & 0 & 0 & 0 & 0 & 0 & 0 & 0 & 0 \\
10 & 22 & 30 & - & 12 & - & - & - & - \\
20 & 61 & 56 & 47 & 27 & 15 & 16 & 16 & 21 \\
30 & 86 & 74 & 65 & 36 & 32 & 31 & 28 & 35 \\
40 & 107 & 90 & 82 & 52 & 46 & 42 & 39 & 47 \\
50 & 124 & 103 & 95 & 62 & 60 & 56 & 47 & 57 \\
60 & 143 & 116 & $105^{*}$ & 72 & 71 & 66 & 53 & 65 \\
70 & - & 124 & $115^{*}$ & 82 & 78 & 73 & 55 & 72 \\
80 & - & 131 & $119^{*}$ & - & 85 & 80 & 59 & 75 \\
90 & - & 137 & & 89 & 85 & - & 77 \\
\hline
\end{tabular}

* tank swung round

Operating pressure: $\quad 344.75 \mathrm{kPa}$

\begin{tabular}{|c|c|c|c|c|c|c|c|c|c|c|}
\hline $\begin{array}{l}\text { Time from } \\
\text { firing(s) }\end{array}$ & \multicolumn{3}{|c|}{$\begin{array}{l}\text { Float positions } \\
\text { at } 5 \mathrm{~m} \text { range }\end{array}$} & \multicolumn{3}{|c|}{$\begin{array}{l}\text { Positions } \\
\text { @10m }\end{array}$} & \multicolumn{4}{|c|}{$\begin{array}{l}\text { Positions } \\
\text { @ } 15 \mathrm{~m}\end{array}$} \\
\hline 0 & 0 & 0 & 0 & 0 & 0 & 0 & 0 & 0 & 0 & 0 \\
\hline 10 & 22 & 28 & 20 & 22 & 21 & 28 & 14 & 18 & 12 & 15 \\
\hline 20 & 45 & 54 & 61 & 46 & 56 & 52 & 53 & 38 & 37 & 44 \\
\hline 30 & 65 & 77 & 85 & 73 & 79 & 69 & 92 & 55 & 63 & 70 \\
\hline 40 & 82 & 100 & 106 & 94 & 109 & 94 & 116 & 70 & 84 & 92 \\
\hline 50 & 98 & 119 & 124 & 110 & 129 & 112 & 140 & 87 & 99 & 110 \\
\hline 60 & 111 & 136 & 141 & 124 & 147 & 128 & 158 & 99 & 115 & 130 \\
\hline 70 & 121 & 148 & 153 & 135 & 162 & 139 & & 110 & 127 & 141 \\
\hline 80 & 131 & 160 & & 140 & 177 & & & 116 & 137 & \\
\hline 90 & 137 & & & & & & & & & 145 \\
\hline 100 & 144 & & & & & & & & & \\
\hline
\end{tabular}


Table No. 10a

Operating pressure : $413.7 \mathrm{kPa}$

\begin{tabular}{|c|c|c|c|c|c|c|c|c|c|c|c|}
\hline $\begin{array}{l}\text { Time } \\
\text { from } \\
\text { firing } \\
\text { (s) }\end{array}$ & $\begin{array}{l}\text { Float } \\
\text { @ } 5 \mathrm{~m}\end{array}$ & & $\begin{array}{l}\text { Pos } \\
\text { (i) } 1\end{array}$ & $\begin{array}{l}\text { ition } \\
\text { Dm }\end{array}$ & & & & & $\begin{array}{l}\text { ositi } \\
15 \mathrm{~m}\end{array}$ & & \\
\hline 0 & 0 & 0 & 0 & 0 & 0 & 0 & 0 & 0 & 0 & 0 & 0 \\
\hline 10 & 40 & 47 & 22 & 34 & 10 & 22 & - & - & - & - & - \\
\hline 20 & 79 & 82 & 32 & 66 & 41 & 43 & 20 & 47 & 18 & 25 & 43 \\
\hline 30 & 110 & 118 & 60 & 99 & 66 & 66 & 45 & 68 & 38 & 50 & 63 \\
\hline 40 & 143 & 147 & 77 & 124 & 91 & 85 & 66 & 91 & 57 & 68 & 88 \\
\hline 50 & - & - & 95 & 149 & 112 & 107 & 82 & 112 & 79 & 78 & 107 \\
\hline 60 & - & - & 108 & 168 & 131 & 121 & 96 & 123 & 98 & 94 & 128 \\
\hline 70 & - & - & 117 & - & 142 & 135 & 111 & 138 & 116 & 105 & - \\
\hline 80 & $=$ & - & 124 & - & - & 146 & 123 & 147 & 126 & 112 & - \\
\hline 90 & - & - & 132 & - & - & - & 135 & 157 & - & 120 & - \\
\hline 100 & - & - & - & - & - & - & 146 & 167 & - & - & - \\
\hline
\end{tabular}

Summary of averaged displacements. vs. time

\begin{tabular}{|c|c|c|c|c|c|c|c|c|c|}
\hline $\begin{array}{r}\text { time } \\
(\mathrm{s}) \\
\end{array}$ & $(5 \mathrm{~m})^{2}$ & $\begin{array}{l}75.8 \\
(10 \mathrm{~m})\end{array}$ & $\begin{array}{l}\mathrm{Pa} \\
(15 \mathrm{~m})\end{array}$ & $(5 \mathrm{~m}$ & $\begin{array}{r}34 \\
10 \\
\end{array}$ & $\begin{array}{l}75 \mathrm{kPa} \\
(15 \mathrm{~m})\end{array}$ & \multicolumn{3}{|c|}{$\begin{array}{c}413.7 \mathrm{kPa} \\
(10 \mathrm{~m})^{\circ}(15 \mathrm{~m})\end{array}$} \\
\hline 0 & 0 & 0 & 0 & 0 & 0 & 0 & 0 & 0 & 0 \\
\hline 10 & 26 & 12 & - & 23 & 24 & 15 & 44 & 22 & - \\
\hline 20 & 55 & 27 & 17 & 53 & 51 & 43 & 81 & 46 & 31 \\
\hline 30 & 75 & 36 & 32 & 76 & 74 & 70 & 114 & 73 & 53 \\
\hline 40 & 93 & 52 & 44 & 96 & 99 & 91 & 145 & 94 & 74 \\
\hline 50 & 107 & 62 & 55 & 114 & 117 & 109 & - & 116 & 92 \\
\hline 60 & 121 & 72 & 64 & 129 & 133 & 126 & - & 132 & 108 \\
\hline 70 & - & 82 & 70 & 141 & 145 & - & - & - & - \\
\hline 80 & - & - & 75 & - & - & - & - & - & - \\
\hline
\end{tabular}

\# only one set of good readings. 
Figure 17 .

Float tank's displacement vs time.

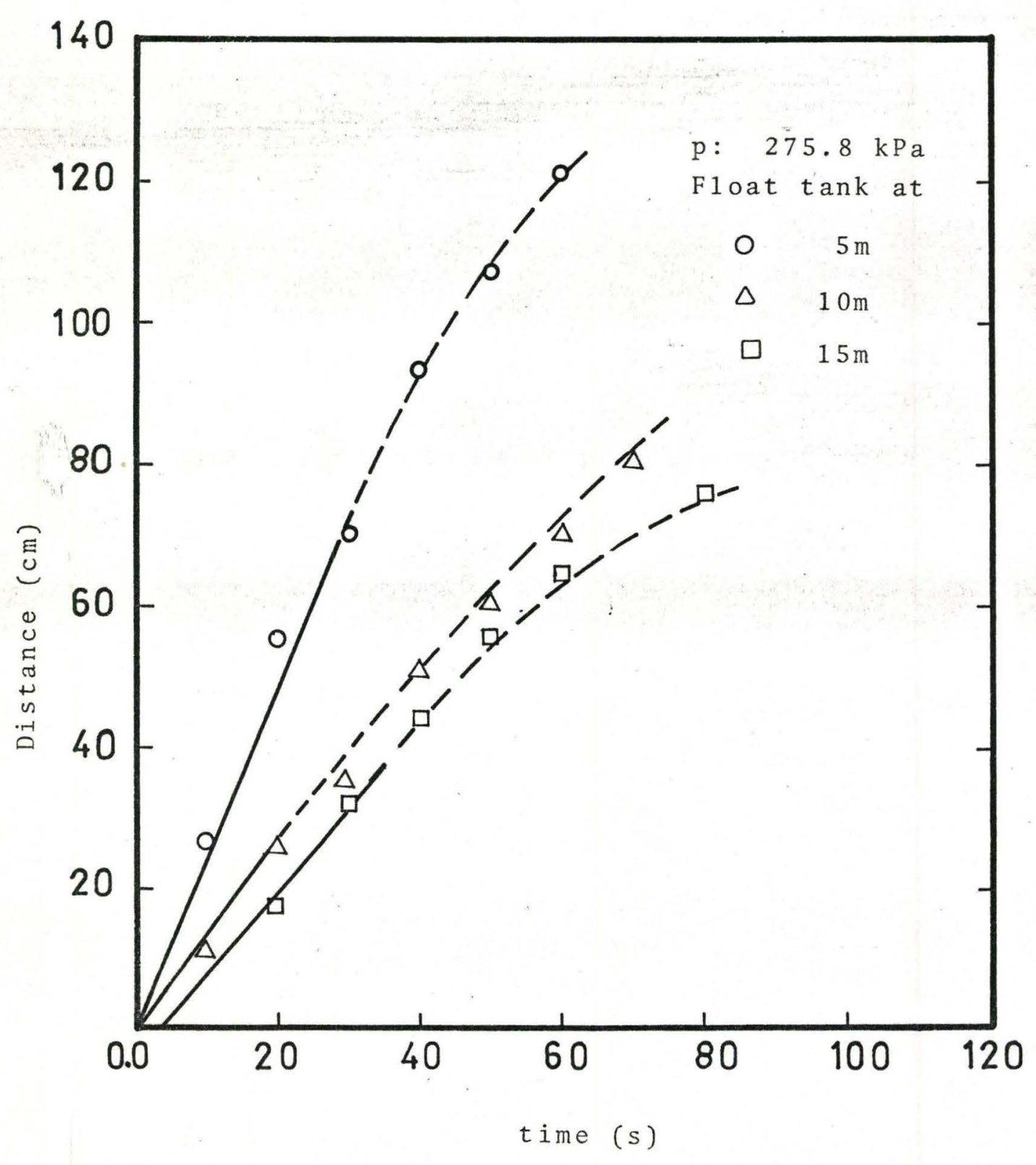


Figure 18 .

Float tank's displacement vs time.
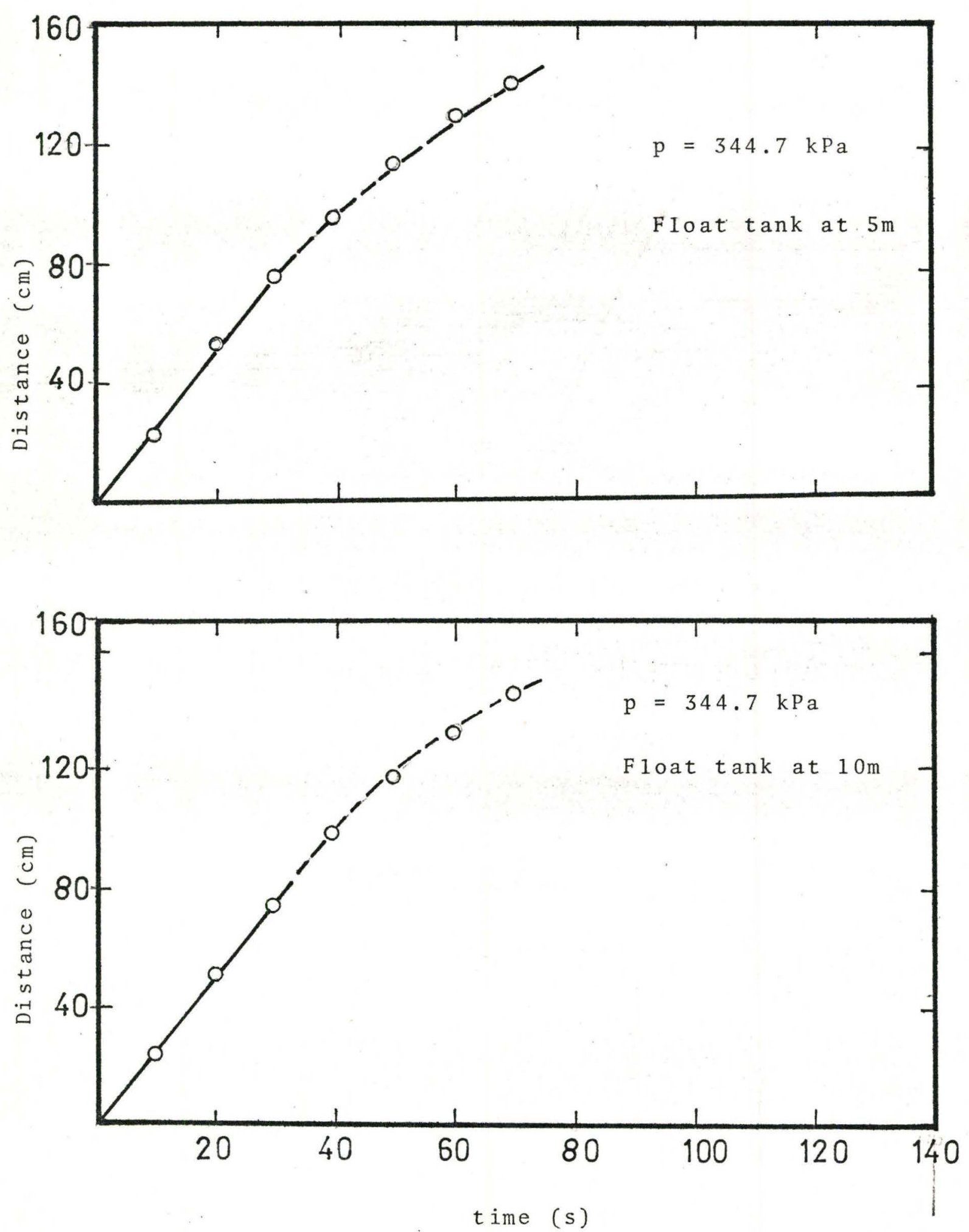
Figure $18 \mathrm{a}$.

Float tank's displacement vs time.

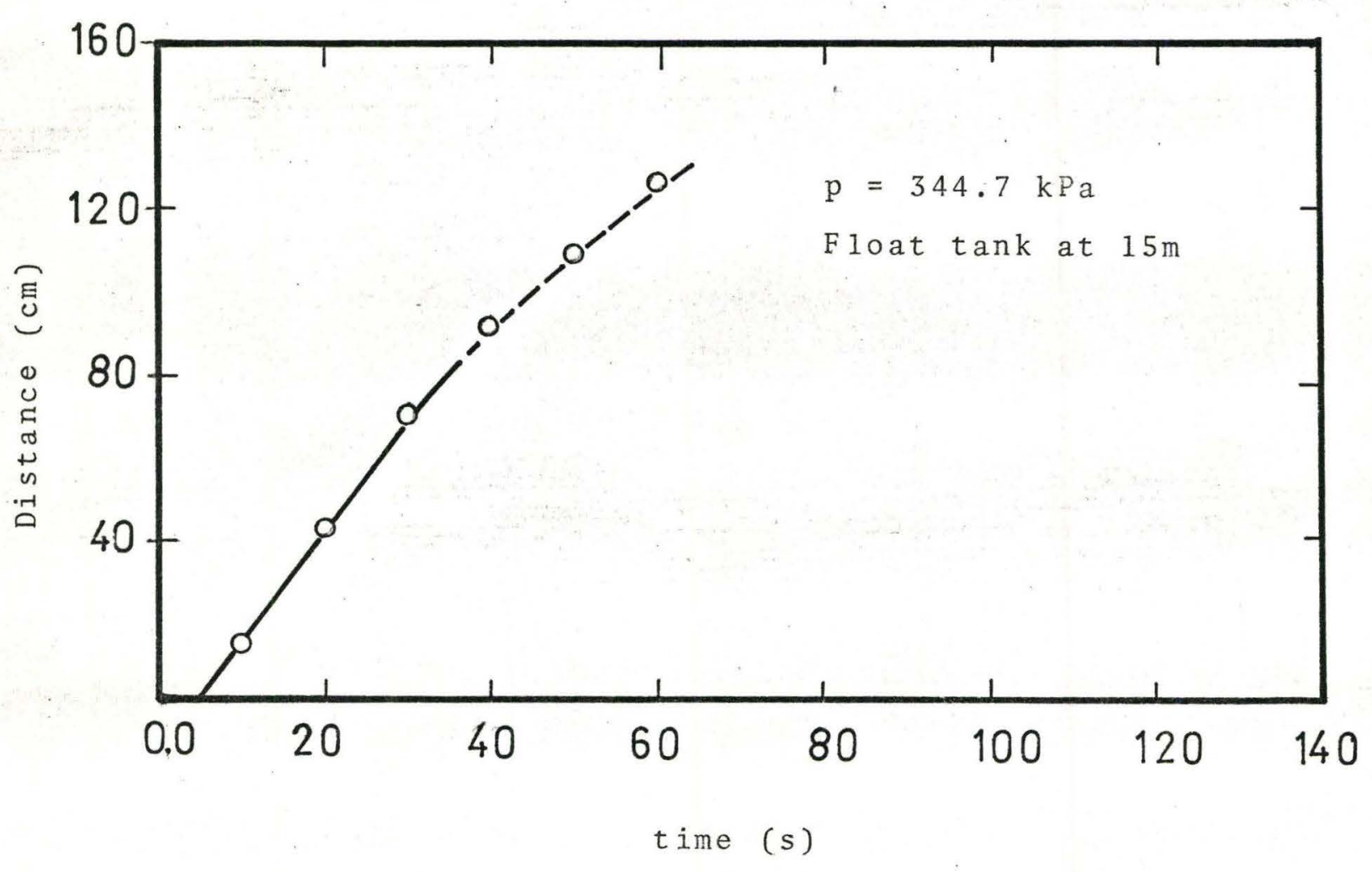


Figure 19.

Float tank's displacement vs time.

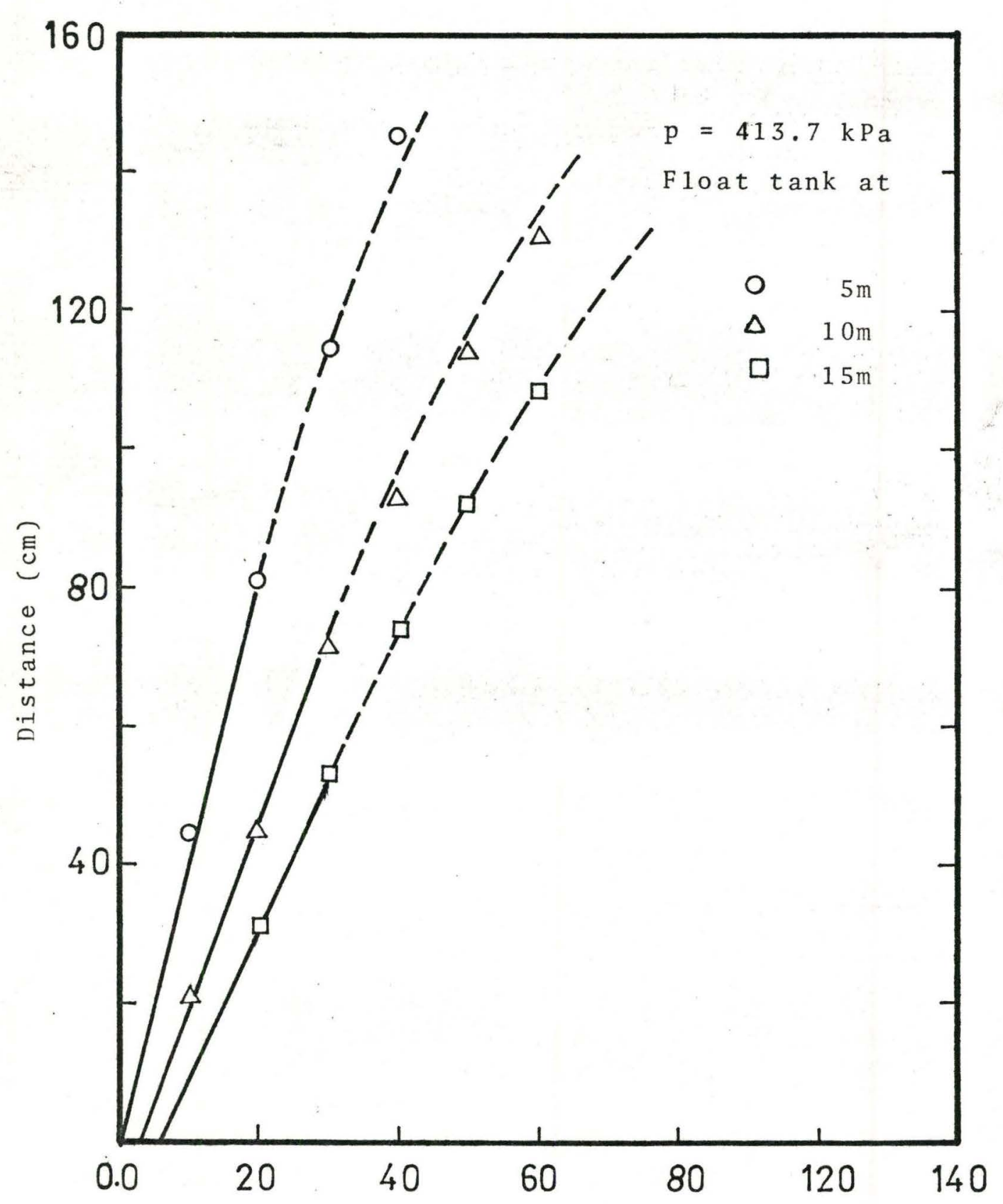




\section{TABLE NO.11}

Determination of Momentum of large vortex rings and comparison with Baird's method.

\begin{tabular}{|c|c|c|c|c|c|c|c|c|c|c|c|c|c|}
\hline \multirow[t]{2}{*}{$\begin{array}{l}\text { Operating } \\
\text { Pressure } \\
\mathrm{p} \\
\mathrm{kPa}\end{array}$} & \multirow{2}{*}{$\begin{array}{l}\quad * \\
\text { Actual } \\
\text { Volume } \\
\text { of Air } \\
\text { displaced } \\
\left(\mathrm{m}^{3}\right)\end{array}$} & \multicolumn{2}{|c|}{$\begin{array}{l}2 x \text { Actual } \\
\text { Volume of Air } \\
\text { displaced }= \\
\text { Volume of } \\
\text { Vortex ring at } x=0\end{array}$} & \multicolumn{2}{|c|}{$\begin{array}{l}\text { Vortex ring } \\
\text { velocity at } x=0 \\
\text { (Table } 8 \text { ) } \\
\text { Laminar | Turbulent }\end{array}$} & \multicolumn{2}{|c|}{$\begin{array}{l}\text { Momentum of Vortex } \\
\text { ring at } x=0\end{array}$} & \multicolumn{3}{|c|}{$\begin{array}{l}\text { F1oat tank's } \\
\text { ve1ocity (Figs.17-19) } \\
\quad(\mathrm{m} / \mathrm{s})\end{array}$} & \multicolumn{3}{|c|}{$\begin{array}{l}\text { Momentum of Vortex } \\
\text { ring calculated } \\
\text { from float tank's } \\
\text { displacement } \\
\text { measurements } \\
\text { (N.S.) }\end{array}$} \\
\hline & & $\begin{array}{c}\text { Vol ume } \\
\left(\mathrm{m}^{3}\right)\end{array}$ & $\begin{array}{l}\text { Mass } \\
(\mathrm{kg})\end{array}$ & $(\mathrm{m} / \mathrm{s})$ & $(\mathrm{m} / \mathrm{s})$ & $(N \cdot s)$ & $(N \cdot s)$ & $5 \mathrm{~m}$ & $10 \mathrm{~m}$ & $15 \mathrm{~m}$ & $5 \mathrm{~m}$ & $\frac{10 \mathrm{~m}}{1}$ & $15 \mathrm{~m}$ \\
\hline 275.8 & .0215 & .0430 & 43.0 & 1.53 & 2.59 & 65.79 & 111.37 & .025 & .012 & .012 & 37.85 & 18.17 & 18.17 \\
\hline 344.7 & .0269 & .0538 & 53.8 & 1.57 & 2.77 & 84.47 & 149.03 & .027 & .025 & .028 & 40.88 & 37.85 & 42.39 \\
\hline 413.7 & .0323 & .0646 & 64.6 & 2.52 & 4.65 & 162.79 & 300.39 & .041 & .026 & .021 & 62.07 & 39.36 & 31.79 \\
\hline 482.6 & .0377 & .0754 & 75.4 & 2.54 & 3.79 & 191.52 & 285.77 & & & & & & \\
\hline
\end{tabular}

* Taken from manufacturer's manual. 
The resulting velocities of the float tank obtained from the initial slopes of these curves are summarised in Table No. 11. Based on these values and with a given effective mass of float tank $(1514 \mathrm{~kg})$, the momentum of vortex rings was calculated from Equation No. 15 and the values are presented in Table 11.

7.2.2 MOMENTUM MEASUREMENT OF THE VORTEX RING AT ORIFICE:

Baird et al (17) suggested that the mass of the ring vortex at the orifice was twice the mass of the displaced fluid from the vortex generator. The volume of displaced fluid was assumed to be equal to that of air injected. In the present case, the volume of air cannon was given to be $.0076 \mathrm{~m}^{3}$ from the manufacturer's manual. In order to obtain the volume of expelled air at a given operating pressure, isothermal expansion of air from the cannon to the vortex generator was assumed and these volumes at appropriate pressures are summarised in Table No. 11. In fact, these volumes are taken from the manufacturer's manual and they are about 3\% higher than they would be when calculated from isothermal expansion criterion. Once the injected air volume was known, the estimated initial masses of the vortex rings were obtained and are given in Table 11. Vortex velocities at $X=O$ (at orifice) were estimated from Equations 12 and 14 and the parameters were obtained from non-linear regression of the distance versus time data as discussed in 7.1. The values of the velocities 
at $\mathrm{X}=0$ for both turbulent and laminar models are reproduced in Table 11 from Table 8. Based on above discussion the momentum of vortex rings was calculated and the results are presented in Table 11. 
CHAPTER 8

\section{DISCUSSION OF RESULTS}

8.1 RANGE AND VELOCITY: The maximum range of any vortex ring in this work was observed to be $55.4 \mathrm{~m}$ at an operating pressure of $344.7 \mathrm{kPa}$. The average range of the rings was, however, between $20 \mathrm{~m}$ to $30 \mathrm{~m}$. In some cases the rings broke up by hitting the surface of the water, while still moving quite fast. Consequently, no systematic relationship between the operating pressure $\mathrm{p}$ and observed range was observed. Average vortex velocities at the orifice based on the laminar model varied between $1.5 \mathrm{~m} / \mathrm{s}$ and $2.5 \mathrm{~m} / \mathrm{s}$ and on the basis of the turbulent model their magnitude was between 2.59 to $4.65 \mathrm{~m} / \mathrm{s}$. The mass of fluid associated with the vortex rings, estimated from the volume of injected air, varied from $43 \mathrm{~kg}$ $43 \mathrm{~kg} /$ vortex to $75.4 \mathrm{~kg} /$ vortex. Both the velocity and mass of the vortex ring tend to increase with operating pressure, and the values are higher based on turbulent model than calculated from laminar model. The turbulent model is considered to give a better representation of vortex behavior ( see next section). These values of mass and velocities are only estimates, nevertheless they suggest that the rings are stable, and that both velocity and mass of the rings are large enough to be used in mixing applications, like blending of oils or possibly destratification of lakes or harbours. 
8.2 LAMINAR VERSUS TURBULENT MODEL FOR THE ESTIMATION OF

VORTEX VELOCITIES: The vortex velocities at $\mathrm{X}=\mathrm{O}$ (at orifice) were obtained from fitted parameters, using Equations 12 and 14 ( see Table 8). Equation (12) was based on the laminar flow model and Equation (14) was based on the turbulent flow model. The parameters were estimated by non-linear regression of the measured data of distance versus time. The one-sided F ratio test was used to compare the variances from both the turbulent and laminar models (see Table 9). The hypothesis was whether or not the variance from the laminar model was greater than the variance from the turbulent model or vice versa. This hypothesis was rejected in three of the four cases ( see Figures 9,10,13,14,15,16) indicating that statistically there was no significant difference between the two models. Upon inspection of these curves, one sees that the predicted values from these models agree with the measured values reasonably well.

The hypothesis was accepted in one case only (operating pressure $344.7 \mathrm{kPa}$; Figures 11 and 12 ) indicating that statistically the turbulent model fitted the measured data better than was the case with the laminar model. Upon inspection of these curves one sees that the predicted values from both the models agree with the measured values well up to 40 seconds or so. However, as the time increased, the predicted values from the turbulent model agree with the measured data reasonably well. ( see point at 
$X=55.4 \mathrm{~m}, t=185 \mathrm{~s})$ whereas the values from the laminar model trailed behind. Such an occurrence was not observed in the three other cases because the data were available only for shorter time intervals for which actually no significant difference was observed in each of the four cases. It appears tentatively that the turbulent model is better suited to predict the velocities of large vortex rings, in other words, a gradual slowing down of the vortex ring occurs by a square-law drag relationship. In the previously described tank mixing experiments with phenolphthalein, a thin trail of eddies was observed behind each descending vortex ring.

8.3 VORTEX RING MOMENTUM ESTIMATION: It was stated by Reynolds (7) that the momentum of a ring vortex remained constant. His contention was that during vortex ring motion, its velocity decreased but the mass of the ring increased by entrainment of ambient liquid. The change in both velocity and mass were said to be such that the momentum was conserved. Unfortunately, he did not indicate how he had measured the momentum, nor was any specific data given. Baird et al (17) confirmed only that the momentum of their rings was conserved only up to a distance of $60 \mathrm{~cm}$.

In this work, it was found ( Figures 17-19, Table 11) that the momentum of the rings decreased 
at firing pressures of 275.8 and $413.7 \mathrm{kPa}$ with distance, although at $344.7 \mathrm{kPa}$ it was fairly constant. According to author's observation the vortex ring diminished in size as it travelled further and further, i.e. contrary to Reynold's observation, the mass of the ring decreased with time. Tentatively, it appears that the mass of the ring does not increase and hence momentum is not conserved.

The measured values of momentum are compared in Table 11 with those calculated based on the estimate of initial mass according to Baird et al (17) and the extrapolation of vortex velocities at $X=0$ for both the laminar and turbulent models. It was found that the measured momentum values were less than the calculated ones. The difference was at least a factor of two and this difference increased with pressure. The calculated values were higher for the turbulent model than those in the laminar model. Although the float tank technique of measuring the momentum is not claimed to be very accurate (possibly $\pm 20 \%$ ), this does not account for the enormous descrepancies in values shown in Table 11. Possible explanations for this are 1) uncertainty as to whether the velocity fit equations can be extrapolated right back to the orifice 2) a question of whether the volume of the ring is in fact equal to twice the volume of air injected as was suggested by Baird et al (17). In other words, the ring formation process may be different for the large vortices than was the case with small vortices (17). Also 
the sudden expansion of air at sonic velocities from the air cannon through the 2 " rubber hose may cause a great deal of energy loss and turbulence inside the steel drum which could have affected vortex ring formation process. 3) Some kind of energy loss may have occurred due to deformation of the orifice; it was once observed that the orifice plate deformed and broke away from the drum after several tests at $482.6 \mathrm{kPa}$. 
CHAPTER 9

CONCLUSIONS

9.1 CONCLUSIONS BASED ON MIXING TESTS: On the basis of tests carried out in the laboratory tank, vortex rings are a promising means of mixing stratified fluids. The volumetric efficiency is in general greater than unity, i.e. that the amount of fluid discharged as rings to achieve good mixing is less than the volume of light fluid.

The energy efficiency, based on the energy of the rings and the theoretical potential energy needed to mix a stratified fluid is 9 to $30 \%$, which is considerably better than the efficiency obtained for impeller mixing. Efficiency is improved by allowing the vortex ring to dissipate most of its energy before it collides with the base of the tank.

9.2 CONCLUSIONS BASED ON LARGE SCALE HYDRODYNAMIC TESTING:

Vortex rings shot from a $25.4 \mathrm{~cm}$ orifice horizontally under water have ranges up to $55 \mathrm{~m}$ and commonly $20-30 \mathrm{~m}$ (about 100 orifice diameters). This indicates suitability for mixing applications in very large tanks or lakes. The suggestion by Reynolds (7) that vortex rings conserve their linear momentum was not confirmed, however. The distance versus time data are consistent with a square-law (i.e. turbulent) drag mechanism. 
The compressed Air Cannon (Martin Engineering Co. ) is a convenient means of generating large and powerful rings, but the sonic-velocity discharge of air appears to lead to some energy losses in the vortex generator. A more controlled valving arrangement might prove more energy-efficient but would have a higher capital cost. 


\section{REFERENCES}

1. Fossett, H., Trans. Instn. Chem. Engrs, 29,322 (1951).

2. Rushton, J.H., Petroleum Refiner 33,101 (1954).

3. Oldshue, H.E., Chemical Engr. Prog. 52,481 (1956).

4. Wilson, N.G., The Oil and Gas Journal, 165, Nov. 8,1954

5. Hamilton Harbour Study, Ontario Ministry of the Environment, 1975. Water Resources Branch; St. Clair Avenue West, Toronto. 40p.

6. Rogers, W.B., Amer.J.Sci. 26, 246(1858).

7. Reynolds, 0., Nature, $\quad$ 14,477 (1876)

8. Maxworthy, T., J.Fluid Mech., 81, 465 (1977)

9. Honji,H., and Tatsuno, M., J. of the Physical Society of Japan, 41, No.6,2121(1976).

10. Oshima, Y., and Asaka,S., J. of the Physical Society of Japan, 42, No.2,708(1977)

11. Manins, P.C. J. Fluid Mech. 74, part 3, 547(1976)

12. Reed Jr., X.B., Ponter, A.B., and Vijayan, S. Zeitschrift"Tenside" 11. Jahrgang 1974 Heft 6 Pages 305 to 307

13. Iinden, P.F. J. Fluid Mech. 60,part 3, 467(1973)

14. Anonymous, Nature 226,584(1970)

15. Turner, J.S., Mech.Eng.Sci. 2,97 (1960)

16. Kendig,F., Saturday Review, March 18th, P.40 (1972)

17. Baird, M.H.I., Wairegi,T., and Loo, H.J.

The Canadian J. Chem. Engg. 55,19(1977) 
18. Fox,E.A. and Gex,V.E., A.I.Ch.E.Journal, 2,No.4,539(1956).

19. "Vortex Mixing in Hamilton Harbour" written by Dr. M.H.I. Baird, Chemical Engineering Department, McMaster University, Hamilton, Ontario. Date: September 6th, 1977 


\section{NOMENCLATURE}

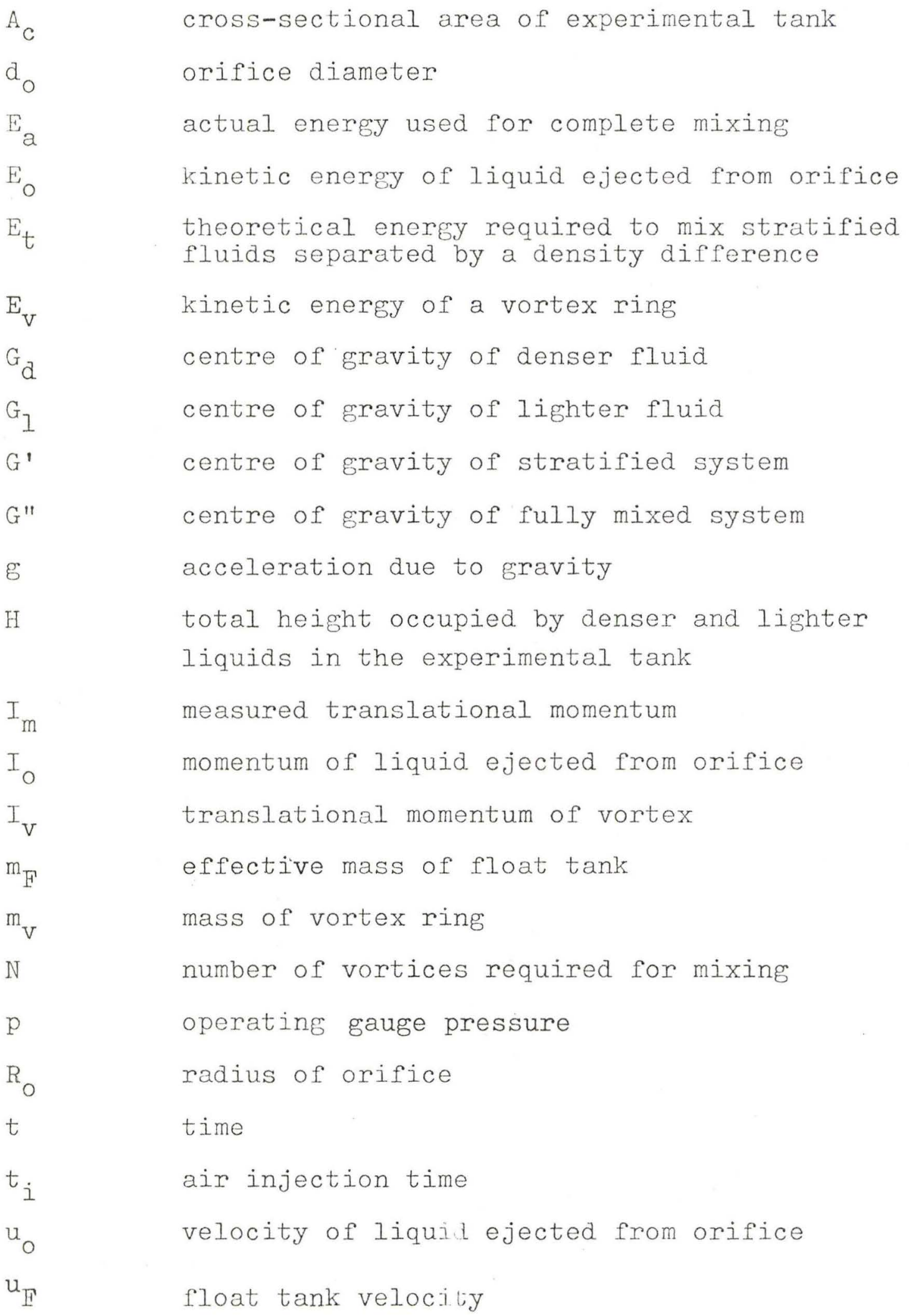




$\begin{array}{ll}u_{v} & \text { vortex ring velocity } \\ v & \text { volume } \\ v_{\text {tot }} & \text { total volume } \\ v_{t} & \text { volume of lighter fluid } \\ v_{d} & \text { volume of denser fluid } \\ X & \text { distance }\end{array}$

$A, B, P, Q$ parameters

Greek letters

$\begin{array}{ll}\Delta \mathrm{V} & \begin{array}{l}\text { volume of air injected into vortex generator } \\ \text { per vortex }\end{array} \\ \rho & \text { density of liquid } \\ \rho_{\mathrm{d}} & \text { density of denser liquid } \\ \rho_{1} & \text { density of lighter liquid } \\ \varepsilon & \text { energy efficiency of mixing } \\ \varepsilon_{\mathrm{v}} & \text { volumetric efficiency of mixing } \\ \phi & \text { volume fraction occupied by denser liquid }\end{array}$

